\title{
The Business Cycle Human Capital Accumulation Nexus and its Effect on Hours Worked Volatility
}

\author{
by \\ Diana Alessandrini \\ Department of Economics, Auburn University \\ diana.alessandrini@auburn.edu \\ Stephen Kosempel \\ Department of Economics and Finance, University of Guelph \\ kosempel@uoguelph.ca \\ Thanasis Stengos \\ Department of Economics and Finance, University of Guelph \\ tstengos@uoguelph.ca
}

\section{Department of Economics and Finance University of Guelph Discussion Paper 2014-07}

Accepted Manuscript@ Journal of Economic Dynamics and Control

(C) 2015, Elsevier. Licensed under the Creative Commons Attribution-Non Commercial-

No Derivatives 4.0 International http://creativecommons.org/licenses/by-nc-nd/4.0/

The final publication of this article is available at www.elsevier.com

DOI: http://dx.doi.org/10.1016/j.jedc.2014.11.004 


\title{
The business cycle human capital accumulation nexus and its effect on hours worked volatility*
}

\author{
Diana Alessandrini $^{\dagger 1}$, Stephen Kosempel ${ }^{2}$, and Thanasis Stengos ${ }^{2}$ \\ ${ }^{1}$ Department of Economics, Auburn University \\ ${ }^{2}$ Department of Economics and Finance, University of Guelph
}

August 2014

\begin{abstract}
This paper studies hours worked volatility and the cyclicality of human capital investments by embedding a Ben-Porath life-cycle model of human capital accumulation into an RBC setting. Agents differ across two dimensions: age and productivity in learning. Our results show that individuals invest more in human capital during economic downturns. However, human capital accumulation is more counter-cyclical for young and low-productivity individuals because they face a lower opportunity cost of education and a higher marginal product of human capital. These results are confirmed empirically using US data from the Current Population Survey and the American Time Use Survey. In addition, the paper contributes to the RBC literature by showing that the model's business cycle properties, in particular hours worked volatility, are sensitive to assumptions of heterogeneity. Introducing heterogeneity in productivity increases the volatility of aggregate hours worked and changes the life-cycle profile for hours volatility to better match the data.
\end{abstract}

JEL classification: J22, J24, E32

Keywords: hours worked volatility; human capital accumulation; business cycles; heterogeneous agents

${ }^{*}$ We are very grateful to the anonymous referees for detailed comments and suggestions. We thank participants at the 2012 CEA, EALE, RCEA and ACEA meetings for comments. The third author acknowledges support from the SSHRC insight grant program. Financial support for this project obtained through the University of Guelph's SSHRC Institutional Grant is also gratefully acknowledged.

${ }^{\dagger}$ Corresponding Author. Address: Department of Economics, 0337 Haley Center, Auburn University, AL, 36849, USA. Phone number: +1(334) 844-2921. Fax number: +1(334) 844-4615. Email: diana.alessandrini@auburn.edu 


\section{Introduction}

Among US high-school students age 16 to 24 who graduated in 2009, 70.1\% enrolled in college in October 2009. This is the historical high for college enrollment rate since 1959. At the same time, the unemployment rate reached a level of $10 \%$ in October 2009 which is also the maximum level for unemployment in the recent financial crisis ${ }^{1}$. This fact seems to be consistent with several studies in the literature regarding the cyclicality of post-secondary education (PSE). On one hand, during a recession high unemployment decreases the opportunity cost of education and people substitute work with schooling (Heylen and Pozzi, 2007). On the other hand, family income is lower and students may not be able to afford the cost of education (Christian, 2007). If liquidity constraints are not too tight, economic theory suggests that PSE enrollment should be countercyclical.

Canton (2002) confirmed that uncertainty leads agents to accumulate more human capital to compensate for future income losses. DeJong and Ingram (2001) showed that, in the presence of a positive TFP shock, human capital is more expensive than physical capital. Thus agents decrease study hours and accumulate less human capital. Empirically, the results are more controversial. Mattila (1982), Polzin (1984), Kane (1994) and Edwards (1976) found no impact of business cycles on college enrollment in US. Instead, more recent papers (Betts and McFarland, 1995; Dellas and Sakellaris, 2003; Dellas and Koubi, 2003; Méndez and Sepúlveda, 2012) found evidence in favor of counter-cyclicality.

The cyclicality of schooling decisions has received particular attention in the literature because of its interesting implications. Economic downturns are bad for the economy. However, if enrollment rates are counter-cyclical, then economic crises are also the most efficient time to accumulate human capital and produce more skilled workers. This paper further investigates the topic both theoretically and empirically by focusing on heterogeneity among agents. The main result is that business cycles impact different types of agents in different ways. Young and lowproductivity individuals are more likely to enroll in PSE during an economic downturn because

\footnotetext{
${ }^{1}$ Source: US Bureau of Labor Statistics.
} 
they face a lower opportunity cost of education. In contrast, high-productivity agents and older people with work experience earn higher wages and are less likely to leave the labor market. As a result, their labor supply is less volatile compared to the rest of the population. This fact is consistent with US data and our model is able to replicate this empirical regularity for the first time. To the best of our knowledge, this is the first theoretical and empirical study that analyzes the heterogeneous impact of business cycles on schooling decisions. In the existing literature, the only paper that looked at heterogeneity among agents in this context is Christian (2007), who distinguished between low and high income individuals. Using data from the October Supplement of the Current Population Survey (CPS), he found that enrollment decisions are more pro-cyclical for low income individuals compared to high income individuals.

The current paper also contributes to the RBC literature by studying the impact of heterogeneity and the cyclicality of education on the volatility puzzle. One of the main shortcomings of RBC models is their inability to correctly predict hours worked volatility. Specifically, these models predict a volatility that is lower compared to empirical estimates. Several solutions have been proposed in the literature, including the introduction of indivisible labor (Hansen 1985) or alternatives to market production (e.g. home production and education. See Benhabib et al., 1991; Perli, 1998; DeJong and Ingram, 2001; Einarsson and Marquis, 1998). These solutions assume that the RBC model systematically underestimates the volatility by excluding important factors that influence labor supply. However, the model may underestimate the volatility only for certain groups of individuals. In the data, labor supply is more volatile for young compared to middle-age individuals. This fact cannot be captured within a representative-agent framework. Therefore, introducing heterogeneity in the model may help to explain the volatility puzzle. Recent papers (e.g. Hansen and İmrohoroğlu, 2009; Gomme et al., 2005; Maliar and Maliar, 2001) have looked at the volatility puzzle from this perspective.

We further investigate the topic by looking at human capital accumulation and heterogeneity among agents. With respect to the existing literature we consider a new type of heterogeneity. Specifically, we embed a Ben-Porath (1967) model of human capital accumulation into a lifecycle RBC setting. Our analysis most closely resembles the work of Hansen and İmrohoroğlu 
(2009), but we build on their work by incorporating an additional type of heterogeneity. While they consider heterogeneity across ages only, we model heterogeneity in productivity both within and between ages. Moreover, in contrast to their paper, our focus is on formal education rather than learning-by-doing or on-the-job training. Our results show that introducing heterogeneity within ages increases the volatility of aggregate hours worked and changes the profile for hours volatility to better match the data. The presence of low-productivity agents is particularly important to improve the model's predictions with respect to hours worked volatility.

The rest of the paper is organized as follows. The model is presented in Section 2. The theoretical results and the implications about hours worked volatility are presented in Section 3. Section 4 discusses various sensitivity analyses. The model's predictions regarding the cyclicality of human capital investments are tested empirically using US data in Section 5. Finally, Section 6 concludes by summarizing the main results.

\section{The Model}

Every year a new generation of equal size is born. Agents face an uncertain life span and may live for a maximum of $S_{\max }$ periods. In each period, they are endowed with one unit of time they can allocate among leisure, work and education. Individuals can work and study at the same time during their working life. Conditional on survival, they must retire at age $S_{r}$. During retirement, labor supply and education are absent and the time endowment is completely allocated to leisure. In any period, there are two types of capital: physical and human capital. Physical capital is accumulated during life through investment, while the human capital stock increases by allocating time to education. Agents start their life with no physical capital and leave no bequests at the end of their life. Instead, the initial human capital stock is positive. This is due to the fact that period 1 in the model represents the 18 -year-old cohort in the data. Since our focus is on post-secondary education, a birth age of 18 seems the appropriate choice. Therefore, the positive initial human capital stock captures the amount of human capital accumulated during mandatory education. At the beginning of their life, agents maximize their expected discounted lifetime utility: 


$$
E_{t} \sum_{s=1}^{S_{\max }}\left(\prod_{j=0}^{s-1} \varphi_{j}\right) \beta^{s-1}\left[\frac{\left(c_{t+s-1, s} m_{t+s-1, s}^{\gamma}\right)^{1-\eta}}{1-\eta}\right]
$$

by choosing consumption, investment in human and physical capital, time spent working and studying. The subscripts $t$ and $s$ refer to the time period and age, respectively. Further, $E$ is the expectation operator, $\varphi_{j}$ is the probability of surviving from age $j$ to age $j+1, \beta$ is the discount factor, $c$ is consumption, $m$ is leisure, $\gamma$ is the disutility of non-leisure activities (i.e. working and studying), and $\eta$ is the coefficient of relative risk aversion. The cohort shares, $\theta_{s}$, are constant over time and are determined by the survival probabilities $\left\{\varphi_{j}\right\}_{j=1}^{S_{\max }}: \theta_{s}=\varphi_{s-1} \theta_{s-1}\left(s=2, . ., S_{\max }\right)$ and $\theta_{1}=1-\sum_{s=2}^{S_{\max }} \theta_{s}$, such that the sum of the shares is equal to one.

During the working periods, the sources of income are labor and asset wealth accumulated from investment in physical capital. In turn, labor income depends on efficiency units of labor $n_{t, s} h_{t, s}$, where $n$ is hours worked and $h$ is human capital. During retirement, agents receive interests on physical capital investments. If an agent survives until age $S_{\max }$, she consumes her entire wealth during the last period. However, if the agent dies earlier, the government collects her assets and redistributes them equally among the surviving agents.

Within the same cohort, individuals are heterogeneous because of different levels of ability: high and low. The fractions of high and low types are denoted by $\xi$ and $1-\xi$, respectively. On average, high types are more productive in learning compared to low types. Therefore, they can accumulate more human capital given the same amount of time spent in education, $e$. In particular, human capital accumulation follows:

$$
h_{t+1, s+1, i}=\left(1-\delta_{h}\right) h_{t, s, i}+\Omega_{s, i} h_{t, s, i} e_{t, s, i}^{\phi_{i}}
$$

where $i=\{h i g h, l o w\}$. The parameter $\phi_{i}$ determines how many units of time spent studying effectively contribute to human capital accumulation. This is to capture the quality of education (e.g. number of books in the university library, the student/teacher ratio and the number of laboratories in the university). This parameter may depend on $i$, if high types are more able to take advantage 
(in terms of human capital accumulation) of the quality of education compared to low types. Later $\phi_{i}$ will be calibrated so that the model is consistent with the empirical evidence on household time allocation. Further, $\delta_{h}$ is the depreciation rate of human capital and $\Omega_{s, i}$ refers to the productivity in learning, which depends on both age $s$ and type $i$. Basically, $\Omega_{s, i}$ determines how productive individuals are in accumulating human capital. Indirectly, $\Omega_{s, i}$ also affects the productivity at work. In fact, a higher productivity in learning implies that agents will acquire more human capital over their life cycle, which increases efficiency at work.

Since our focus is on post-secondary education, we abstract from learning-by-doing or on-the-job training. Individuals acquire human capital through education only. Refer to Hansen and İmrohoroğlu (2009) for an analysis of learning-by-doing and on-the-job training in a life-cycle RBC framework. Moreover, we assume that education does not affect utility directly. Agents invest in education only to increase their human capital stock and earn a higher labor income. For this reason, in the retirement period there is no incentive to spend time in education and accumulate human capital, which progressively depreciates as the agent becomes older.

The constraints of the maximization problem are given by the following equations:

$$
\begin{array}{ll}
k_{t+1, s+1, i}=\left(1+r_{t}-\delta\right) k_{t, s, i}+w_{t} n_{t, s, i} h_{t, s, i}-c_{t, s, i}+t r_{t} & \text { budget constraint } \\
h_{t+1, s+1, i}=\left(1-\delta_{h}\right) h_{t, s, i}+\Omega_{s, i} h_{t, s, i} e_{t, s, i}^{\phi_{i}} & \text { human capital accumulation function } \\
m_{t, s, i}+n_{t, s, i}+e_{t, s, i}=1 & \text { time endowment constraint } \\
m_{t, s, i}, n_{t, s, i}, e_{t, s, i} \geq 0 & \text { non-negativity constraints } \\
n_{t, s, i}=0 \text { for } s=S_{r}: S_{\max } & \text { retirement constraint }
\end{array}
$$

where $k$ is physical capital, $r$ is the rental rate of physical capital, $\delta$ is the physical capital depreciation rate, $w$ is the wage rate and $t r$ is the government transfer of assets from deceased agents to surviving agents.

The production sector is given by competitive firms that produce output using efficiency units of labor $L_{t}$ and physical capital $K_{t}$. The production function for the representative firm is CobbDouglas: 


$$
Y_{t}=Z_{t} K_{t}^{\alpha} L_{t}^{1-\alpha},
$$

where $\alpha$ is the physical capital share of output and $Z_{t}$ is the aggregate technology level which follows an AR(1) process: $\ln \left(Z_{t}\right)=\rho \ln \left(Z_{t-1}\right)+\varepsilon_{t}$ with $\varepsilon_{t} \sim N\left(0, \sigma^{2}\right)$. In equilibrium, the prices of the production factors are equal to the marginal products:

$$
\begin{gathered}
w_{t}=(1-\alpha) Z_{t} K_{t}^{\alpha} L_{t}^{-\alpha}, \\
r_{t}=\alpha Z_{t} K_{t}^{\alpha-1} L_{t}^{1-\alpha} .
\end{gathered}
$$

\subsection{The equilibrium}

Given the initial physical and human capital stocks distributions, and the productivity sequence $\Omega_{s, i}$, the equilibrium is a collection of policy rules for each ability type $i, c_{s, i}\left(k_{s, t, i}, h_{s, t, i}, K_{t}, L_{t}, z_{t}\right)$, $n_{s, i}\left(k_{s, t, i}, h_{s, t, i}, K_{t}, L_{t}, z_{t}\right), e_{s, i}\left(k_{s, t, i}, h_{s, t, i}, K_{t}, L_{t}, z_{t}\right), h_{s+1, i}\left(k_{s, t, i}, h_{s, t, i}, K_{t}, L_{t}, z_{t}\right)$ and $k_{s+1, i}\left(k_{s, t, i}, h_{s, t, i}, K_{t}, L_{t}, z_{t}\right)$, and the prices of production factors $\left\{w_{t}, r_{t}\right\}$ such that:

1. The individual policy rules solve the household's maximization problem.

2. Prices $\left\{w_{t}, r_{t}\right\}$ solve the representative firm's maximization problem.

4. The market-clearing condition is satisfied:

$$
Z_{t} K_{t}^{\alpha} L_{t}^{1-\alpha}=C_{t}+K_{t+1}-(1-\delta) K_{t} .
$$

5. Individual decisions are consistent with aggregate outcomes:

$$
\begin{gathered}
L_{t}=\sum_{s=1}^{S_{r}-1}\left(n_{s, t, h i g h} h_{s, t, h i g h} \xi+n_{s, t, l o w} h_{s, t, l o w}(1-\xi)\right) \theta_{s}, \\
K_{t}=\sum_{s=1}^{S_{\text {max }}}\left(k_{s, t, h i g h} \xi+k_{s, t, \text { low }}(1-\xi)\right) \theta_{s} .
\end{gathered}
$$




\subsection{Calibration}

The calibration is target to US data and it is consistent with the standard practice in the RBC literature. One model period corresponds to one year in reality ${ }^{2}$. The calibrated values are reported in Table 1. In particular, survival probabilities are from Bell and Miller (2002). $S_{\max }$ is set to 60 years in order to match the life expectancy at age 18 of males born in 1960 estimated by Bell and Miller (2002). $S_{r}$ is set to 47 to target the ratio of retired people to total active population estimated from 1990 Population Census. Section 4.2 extends the analysis to endogenous retirement decisions. The fraction of high types, $\xi$, is set to 0.58 . This is the average fraction of high-school graduates enrolling in college during the period 1962-2012 (Bureau of Labor Statistics). We experimented with other values for $\xi$ as well. However, the properties of the model are qualitatively the same as discussed in Section 4.3.

The discount factor and the depreciation rate of physical capital are set to 0.969 and $6 \%$, respectively, so that in the model the average physical capital to output ratio is 3 and the average annual real interest rate is $6 \%$. These values imply a capital share of output of 0.36 . The disutility of nonleisure activities, $\gamma$, is chosen to target the average time spent working to 0.33 . The parameters for the Solow residual are chosen to be $\rho=0.814$ and $\sigma=0.0142$. These parameters are equivalent to the values estimated by Prescott (1986) for quarterly frequencies ${ }^{3}$. Finally, the risk aversion parameter, $\eta$, is set to target US output volatility. The calibrated parameter is within the range of values commonly used in the literature, $\eta \in(1,3)$.

The productivity sequence is calibrated using the human capital accumulation function (eq. 2) evaluated at the steady state:

$$
\Omega_{s, i}=\frac{h_{s+1, i}^{*}-\left(1-\delta_{h}\right) h_{s, i}^{*}}{h_{s, i}^{*} e_{s, i}^{* \phi_{i}}} .
$$

where $e_{s, i}^{*}$ is the average time spent studying for each age $s$ and ability type, and it is computed using annual data from the American Time Use Survey (ATUS 2003-2012). Specifically, it refers to the time spent for taking classes and doing homework/research to obtain a degree, certification

\footnotetext{
${ }^{2}$ This is consistent with previous papers in the literature, e.g. Gomme et al. (2005) and Hansen and İmrohoroğlu (2009).

${ }^{3}$ See Heer and Maussner (2009), page 549.
} 
or license $\mathrm{H}^{4}$. It is computed as a fraction of the total available time (i.e. 24 hours/day). The efficiency weights, $h_{s, i}^{*}$, are estimated following the methodology proposed by Hansen $(1993)^{5}$ and using data on hourly earnings from the Panel Study of Income Dynamics (PSID) 1967-20086 . Hansen (1993) did not distinguish between high and low types. His methodology produces one sequence of $h_{s}^{*}$ for the whole economy. However, the procedure has been extended in order to distinguish between ability types, which are empirically defined as follows. An individual is considered to be a high type if she has received a college degree or if she is currently attending college. Instead, low types have at most an associate degree from a non-academic program (i.e. vocational/professional program $)^{7}$. The sequence for $h_{s, i}^{*}$ is also used to calibrate the initial levels of human capital for high and low types so that the model generates the same initial stock of human capital as in the data.

Regarding the depreciation of human capital, $\delta_{h}$, there is no agreement in the literature. Estimates vary from 0.005 to $0.047^{8}$. All values in this range generate results that are qualitatively the same. However, by setting $\delta_{h}=0.005$ the model is more able to replicate the empirical profile for study hours (see Figure 1). For this reason, the results presented in the paper are based on $\delta_{h}=0.005$. The parameter $\phi_{i}$ is calibrated to target the average time spent studying during the working life, $e^{*}$, from ATUS. As confirmed in the data, $e^{*}$ depends on ability: $e_{\text {high }}^{*}=0.017>e_{\text {low }}^{*}=0.003$. The parameters $\phi_{\text {high }}$ and $\phi_{\text {low }}$ are set to match these two statistics. In Section 4.1 we perform a sensitivity test to show how robust the results are to the adoption of a common $\phi$ value $\left(\phi=\phi_{\text {high }}=\right.$ $\left.\phi_{\text {low }}\right)$.

Once we know $\delta_{h}, h_{s, i}^{*}$ and $e_{s, i}^{*}$, the calibration can be summarized as follows. We make an initial

\footnotetext{
${ }^{4}$ Activity codes: 060101 and 060301 . These include attending a seminar/class/practicum/internship/course, taking a field trip, writing exams, taking on-line courses, talking to classmates or teacher, attending a study group, organizing notes, reading, studying, writing a paper or essay.

${ }^{5}$ Averages of $e_{s, i}^{*}$ and $h_{s, i}^{*}$ are first obtained for five age groups (20-24, 25-34, 35-44, 45-54, 55-62) and the two productivity types. These values are then interpolated to obtain one value for each single age and type.

${ }^{6}$ Data for hourly earnings are missing for the following years: 1992, 2003, 2005 and 2007. Hourly earnings are converted in 1967 constant dollars.

${ }^{7}$ Therefore, high types include college students and individuals with a college degree, Bachelor's degree, Master's degree, professional school degree or Doctoral degree. Low types include individuals without a high-school diploma, with a high-school diploma, with an associate degree from a non-academic program, and individuals who attended college in the past but did not graduate.

${ }^{8}$ Estimates of the human capital depreciation rate vary within 1\%-3.4\% in Johnson and Hebein (1974), 0.5\%4.3\% in Haley (1976), 0.7\%-4.7\% in Heckman (1976).
} 
guess of $\phi_{i}$ to generate a series for $\Omega_{s, i}$ and then run a simulation to obtain a profile for $e_{s, i}$. If the average time devoted to education does not match the data (i.e. 0.017 for high types and 0.003 for low types), we update our guess for $\phi_{i}$ and continue until convergence.

This calibration of $\Omega$ allows the model to generate a life-cycle profile for $h$ that closely follows its empirical counterpart, as measured in Hansen (1993). Given $\delta_{h}, \phi$ and $e_{s, i}^{*}$, the productivity in learning is set to match the life-cycle profile for efficiency weights (i.e. $h_{s, i}^{*}$ ) for the two ability types. In turn, this affects the wage profile. Therefore, the model is also able to match the lifecycle profile of wages quite well. Figure 4 shows the model's performance in matching the data. The estimated efficiency weights, $h_{s, i}^{*}$, are plotted in the left panel of Figure 2. The efficiency at work increases when agents are young, has a peak around the middle age and then it starts to decline. Further, high types are more efficient at work than low types of the same age. The right panel shows the calibrated productivity sequence, $\Omega_{s, i}$, obtained from equation 14 . Clearly, the productivity in learning depends on age: it decreases as the agent becomes older because of the negative impact of aging on learning abilities. Further, the productivity is higher for high types until age 40. In fact, the difference in productivity between the two types decreases as individuals age. After age 40, there is no significant difference between the two types.

\subsection{Solution method}

The non-stochastic steady state (i.e. $Z=1$ ) in the 60-period Overlapping Generations model has been computed using a guess and verify method. The algorithm can be summarized as follows. Firstly, given a set of parameter values, we guess the steady-state aggregate levels of labor in efficiency units $L^{*}$ and physical capital $K^{*}$. Secondly, we compute the factor prices and solve the household maximization problem for the two types separately by using backward induction. Thirdly, we compute the aggregate values for labor in efficiency units and physical capital. Finally, the initial guesses are updated using the computed aggregate values and the procedure is repeated until convergence.

In order to analyze the effect of business cycles on human capital accumulation, a negative technology shock has been introduced in the model. The transitional dynamics are computed by log- 
linearizing the first order conditions around the non-stochastic steady state. The impulse response functions are then obtained to describe the dynamics that lead the economy to the steady state after the shock. The results are discussed in the next section.

\section{Results}

The non-stochastic steady state is described in Table 2. Figure 3 shows the steady-state levels for the main variables by age and productivity type. Since high types are very productive in learning compared to low types, they spend more time in education and accumulate more human capital in the steady state. Further, at the beginning of their life, they work less and borrow more physical capital to "finance" education. Although there are no direct monetary costs for education, an agent must spend less time working and forgo part of her labor income in order to study. Therefore, high types borrow physical capital to smooth consumption over time. Around age 25, the time spent studying is significantly reduced and the agent starts to invest in physical capital. Figure 4 shows the ability of the model to match the empirical life-cycle profiles for both types for time spent studying, hours worked, wages and human capital. Data on time spent studying are from ATUS 2003-2012. Data on wages and hours worked are from PSID 1967-2008 . Further, the wage profiles have been computed taking into account cohort effects following the methodology in Huggett et al. (2011). Since hours worked and wages have different units in the model and in the data, they have been normalized to 1 at age 20 .

The overall performance of the model is good. Due to the calibration of $\Omega$, the model is able to closely replicate the human capital series. The model is also able to closely match the lifecycle profile of education. However, there are some discrepancies in wages and hours worked, especially later in the life cycle. Since the productivity in learning is low after age 30, the incentive to study is reduced. Eventually agents stop accumulating human capital, which starts to decrease at rate $\delta_{h}$. This leads to a decline in efficiency wages and, therefore, hours worked in the model. However, these declines are not observed in the data. The discrepancy could be due to the

\footnotetext{
${ }^{9}$ Data about hours worked are missing for the following years: 1992-2000.
} 
fact that the model does not include some features of the data that prevent wages and hours from falling (e.g. unions and indivisibilities in labor time). Nevertheless, the model is able to replicate the empirical fact that, on average, hours worked are increasing in skills. This fact is documented in Kydland (1984) and it is confirmed in the PSID sample used to calibrate the model. In the data, low types spend $31.5 \%$ of their time working, while high types allocate $34 \%$ of their time to work. The percentages produced by the model are $31 \%$ and $35 \%$, respectively. In order to analyze how agents' decisions are affected by business cycles, a negative one-standard deviation technology shock has been introduced in the model. Figure 5 shows the impulse response functions for the aggregate economy. The graphs represent the percent deviation of each variable from the steady state after the shock. The curves show that physical capital, investment, consumption and hours worked are pro-cyclical. Instead, time spent studying is counter-cyclical. Individuals invest more in education to accumulate more human capital and compensate for the reduction in labor income due to the shock. This is manly due to the decrease in the opportunity cost of education. During a downturn, the decrease in the wage rate reduces the opportunity cost of education. Individuals substitute work with schooling. As a consequence, human capital accumulation increases in contrast with the decrease in physical capital accumulation. Since the shock reduces the rate of return to physical capital investments compared to the rate of return to human capital investments, agents substitute physical with human capital. This result is consistent with findings in DeJong and Ingram (2001). Thus, the education sector acts as a buffer sector. It allows agents to compensate for the initial reduction in labor income by increasing the human capital stock. The next section builds on these results and analyzes for the first time the behavior of agents separately by ability and age.

\subsection{Differences by ability type and age}

Figure 6 shows the impulse response functions for education by age and productivity type. The top left graph shows the behavior of the average high and low type. The other graphs show the impulse response functions for three age groups: 18-24, 25-34, 35-64 years of age. Time spent studying responds more to the shock for low types than high types. This is due to the fact that, on 
average, high-productivity agents have already accumulated a large amount of human capital before the crisis. They are more efficient at work and they earn a higher labor income. Therefore, it is more expensive for them to reduce hours worked and forgo labor income in order to study and accumulate more human capital. Further, the marginal product of human capital is relatively low for high types. They benefit less by substituting physical capital with human capital. However, there is no significant difference between ability types when individuals are in the age group 3564. This is due to the fact that the payoff to acquiring additional human capital for this age group is small for both types.

\subsection{Implications for hours worked volatility}

Table 3 shows the average business cycle statistics computed from 500 simulations ${ }^{10}$ of four versions of the model, along with annual business cycle statistics from US data. The data about labor supply are from CPS, March Supplement (1962-2012). Hours worked are obtained using the answer to the question "How many hours did you actually work last week?"11. Data for output, consumption and investment are from US Bureau of Economic Analysis (1962-2012). Output is measured by real GDP, consumption by personal consumption expenditures, and investment by gross private domestic investment. Both the actual and the simulated series are transformed by taking natural logarithms and de-trended using the Hodrick-Prescott filter. Following Ravn and Uhlig (2002), the smoothing parameter is set to 6.25. Since ATUS is only available from 2003 until 2013, we are not able to produce reliable business cycle statistics for the time spent studying, $E$. However, the ability of the model to match the empirical evidence regarding the education sector is analyzed in Section 5.

To better understand how human capital accumulation and heterogeneity in learning ability affect business cycle properties, and in particular time allocation, the version of the model outlined in

\footnotetext{
${ }^{10}$ Each simulation consists of 100 periods.

${ }^{11}$ To compute business cycle statistics about labor supply, CPS is preferred to PSID because it has significantly more observations and it is available for a longer period of time. Further, it has information about "actual" hours worked as opposed to "usual" hours worked. The former is preferred because usual hours worked mainly reflect the number of hours reported in the work contract (which could be different than the actual hours) and, therefore, tend to be less volatile than actual hours worked.
} 
Section 2 will be compared to several simplified versions of the life-cycle RBC model. Model1 is the model presented in Section 2. This is our main specification in which agents are heterogeneous in age and productivity in learning. In the second version of the model, Model2, agents are heterogeneous in age only. Thus, individuals of a given age are equally productive in learning. This is the specification that most resembles the model by Hansen and İmrohoroğlu (2009). However, while they look at learning-by-doing and on-the-job training, we focus on formal education. Model3 is a life-cycle RBC model with exogenous human capital. In this case, agents are heterogeneous by age and productivity at work. However, there is no education sector. Therefore, differences in productivity at work (i.e. differences in the human capital stock) are exogenously given and determined by the calibrated human capital life-cycle profile from Figure 3. Model4 refers to a version of the model without human capital in which agents are equally productive over the life cycle.

In summary, Model1 and Model3 include both heterogeneity by age and productivity at work ${ }^{12}$. However, in Model1 differences in productivity at work are endogenously determined; while in Model3 they are exogenously given. Further, Model2 and Model4 include heterogeneity by age with and without human capital accumulation, respectively.

All parameters in the alternative specifications have been re-calibrated following the procedure discussed in Section 2.2, except for the relative risk aversion parameter $\eta$. This parameter is set to match US output volatility in Model1. Since the purpose of this section is to analyze how different versions of the model are able to match business cycle facts, the comparison is possible only if we consider the same value of relative risk aversion ${ }^{13}$. Table 4 reports the calibrated values for the alternative versions of the model.

As shown by Table 3, the volatility of hours worked is underestimated by all models. However, the models with heterogeneity in productivity at school or at work (i.e. Model1 and Model3) can explain a higher percentage of the volatility empirically estimated. The performance of the model

\footnotetext{
${ }^{12}$ Model1 includes heterogeneity by learning productivity, which determines differences in the human capital stock accumulated by agents. This, in turn, generates differences in the productivity at work.

${ }^{13}$ We also experimented with calibrating the parameter to match US output volatility in each version of the model. However, the predictions of the models are qualitatively the same.
} 
with one ability type (i.e. Model2) is very similar to the performance of the model by Hansen and İmrohoroğlu (2009) and the model without human capital (i.e. Model4). Introducing heterogeneity within ages generates differences among agents in terms of the cost of reducing hours worked. Reducing hours worked is cheaper for agents with a lower human capital stock because they give up a lower labor income. Therefore, when the shock hits the economy, these agents reduce hours worked more and their volatility increases. In fact, Model1 and Model3 are consistent with the data in predicting a higher volatility for low types compared to high types. This empirical regularity is also documented in Ríos-Rull (1993). Since low types have accumulated a lower human capital stock in the steady state, it is less expensive for them to reduce hours worked and give up labor income. Their volatility of hours worked is higher compared to high types. At the aggregate level, hours worked volatility increases when we model this type of heterogeneity. Instead, with one ability type (i.e. Model2) the productivity profile is more similar to the profile of high types. Aggregate volatility is lower and remains close to that of high types from Model1. This result suggests that heterogeneity by age is not enough in order to increase the ability of the model to match hours worked volatility. It is important to include heterogeneity by productivity as well. The presence of low types increases aggregate volatility of hours worked.

Maliar and Maliar (2001) showed that hours worked become more volatile by incorporating heterogeneity in physical capital and skills ${ }^{14}$ into an otherwise standard RBC model. Our findings confirm their result in a finite-horizon setting ${ }^{15}$. However, contrary to their results, our model is able to replicate the empirical fact that hours worked are increasing in skills even for low values of the intertemporal elasticity of substitution for consumption. Moreover, since skill differences are endogenous in our model, we are able to provide an explanation for why we observe this type of heterogeneity. Specifically, high-skilled agents are those individuals who have high productivity in learning and spend more time studying. Finally, by introducing schooling in the model, we can also quantify the impact of education on hours worked volatility. We investigate this aspect in

\footnotetext{
${ }^{14}$ Skills refer to efficiency at work, which is set exogenously. In our model, instead, efficiency at work is determined by the human capital stock accumulated by the individual through education. In this case, skills are determined endogenously.

${ }^{15}$ In our framework, heterogeneity in skills is implied by the heterogeneity in productivity because highproductivity individuals accumulate more human capital compared to low-productivity agents.
} 
the next section.

\subsection{The role of schooling}

By comparing Model1 and Model3 we are able to answer another important question: can schooling increase volatility? Since schooling provides an alternative to work, introducing the education sector in the model could increase hours worked volatility. This is certainly true in an RBC model with identical agents (e.g. DeJong and Ingram, 2001; Einarsson and Marquis, 1998). With heterogeneity, instead, the benefits from education differ among agents. As a result, hours worked volatility may not increase at the aggregate level. Table 3 shows that, by introducing schooling in the model, the volatility increases for low types while it decreases for high types. Overall, Model1 produces a lower aggregate volatility compared to Model3. Since low types are more likely to use the education sector as alternative to work, their volatility increases. Instead, the volatility decreases for high types for two reasons. First, high types are less likely to substitute work with schooling compared to low types. Second, high types have a stronger incentive to substitute work with leisure in Model3 when education is absent from the model. When schooling is not an option, high types borrow less capital since they do not need to finance education. Their savings are higher later in life. Thus, when the shock hits the economy, they reduce hours worked more to increase leisure time. In other words, leisure becomes a better alternative to work when education is absent. For these two reasons, aggregate hours worked volatility of high types is lower in Model1 compared to Model3.

These results suggest that hours worked volatility is mainly affected by differences in the human capital stock. Having education in the model increases volatility for certain groups, but it decreases the volatility for other groups. Overall, the impact is negative. This result is in contrast with previous findings on the impact of schooling on hours worked volatility within representativeagent RBC models. In these models, the introduction of education can increase the volatility of hours worked (see Einarsson and Marquis 1998, for example). Within a life-cycle framework this result no longer holds because some agents are less likely to substitute work with schooling (e.g. high types). Nevertheless, Model1 remains our preferred specification because it is able to explain 
why we observe differences in productivity at work among individuals.

\subsection{The volatility profile}

Finally, the introduction of human capital into the baseline RBC model also has some implications regarding the volatility profile. Figure 7 shows the volatility of hours worked (relative to output volatility) by age group. Consistently with the data, the profiles generated by Model1 through Model3 are U-shaped: labor supply is more volatile for young and old agents compared to middle-age agents. Instead, the life-cycle RBC model without human capital, Model4, predicts an increasing volatility profile. The introduction of human capital increases the volatility for young agents who are more willing to reduce hours worked because they earn a lower labor income, are more productive in learning and benefit more from education. As a result, the volatility profile assumes a "U" shape. This result is independent of the type of heterogeneity considered. All models with human capital show a U-shaped profile. This is consistent with Hansen and Imrohoroğlu (2009), who find that the volatility profile is increasing when human capital is constant across agents, while it assumes a "U" shape when human capital differences among agents are introduced in the model. However, the model with heterogeneity within ages produces the closest profile to the data.

\section{Sensitivity analysis}

\subsection{Common $\phi$ value}

In order to test the robustness of the findings to the schooling parameter $\phi$, we have solved the model when $\phi$ is the same for both ability types. Table 4 reports the calibrated parameters for this alternative specification. All parameters are re-calibrated following the procedure described in Section 2.2 with the exception of $\eta$ and $\phi . \eta$ is kept constant, while $\phi$ is set to match the average time spent studying for the aggregate economy. This statistic is obtained from ATUS (2003-2012) and it is equal to 0.008 . Figure 8 shows the impulse response functions for the main variables of 
interest, while the second column of Table 5 reports the business cycle statistics. The results are qualitatively the same as in Model1. The main findings of the model are driven by the productivity in learning, $\Omega$, rather than the exponent $\phi$. Quantitatively, the model with a common $\phi$ value generates a higher volatility of hours worked. Compared to Model1, when $\phi_{\text {high }}=\phi_{\text {low }}$, young high-types study less in the steady state and more during economic contractions ${ }^{16}$. The volatility of education rises, which leads to the increase in $\sigma_{N_{\text {high }}}$. However, the reduction of study hours in the steady state that is predicted by the model is not consistent with the data, as shown in Figure 9. The model is not able to match the life-cycle profile of education even for low values of $\delta_{h}$. Therefore, Model1 remains our preferred specification. Note that this is a conservative choice.

\subsection{Endogenous retirement}

This section presents the results of the model when the retirement decision is endogenous. In this case, agents are free to choose when to retire from work. The purpose is to understand how sensitive the results are to mandatory retirement. All parameters are re-calibrated following the procedure described in Section 2.2, except for $\eta$, and are reported in Table 4. The business cycle statistics are reported in the third column of Table 5. Figure 10 shows the impulse response functions for education.

Exogenous retirement has no impact on the qualitative predictions of the model. Quantitatively, the volatility of hours worked is higher compared to Model1 for two reasons. By extending the working period, agents benefit from education for a longer period of time, which increases the incentive to substitute work with schooling. Further, the volatility of hours worked of older agents is higher. Thus, aggregate volatility increases as we include older agents. However, with endogenous retirement, the fraction of retired people to active population generated by the model is too high compared to the data. For this reason, in our preferred specification, retirement is mandatory. This allows us to correctly match the number of retired people relative to workers. It is also worth mentioning that the average labor force participation rate for individuals aged 65 and over

\footnotetext{
${ }^{16} \phi_{\text {high }}=\phi_{\text {low }}=\phi=0.035$. This value is lower than $\phi_{\text {high }}$ in Model1. Therefore, in the steady state, the incentive to study for young high-types is lower when we do not distinguish between $\phi_{\text {high }}$ and $\phi_{\text {low }}$.
} 
is $14 \%$ for the period $1962-2012^{17}$. Therefore, by setting exogenous mandatory retirement at age 47 in the model (and 64 in reality), only a small fraction of the population is excluded from our analysis.

\subsection{The fraction of high types}

In this section we consider two alternative values for $\xi$. In the baseline model $\xi=0.58$, which is the fraction of high-school graduates who enrolled in college during the period 1962-2012. Alternatively, one could calibrate this parameter to match some other targets. For example, we could use scores from cognitive tests, such as the Armed Forces Qualification Test (AFQT). By using data from the National Longitudinal Survey of Youth 1979 (NLSY79), we reset $\xi$ to 0.42 to match the fraction of individuals with an AFQT score above the mean score in the year 1980, when the test was administered ${ }^{18}$. Alternatively, using U.S. Census Bureau data, $\xi$ could be set to 0.225 to match the fraction of Americans with a college degree calculated over the period 1962-2012. In both cases, $\xi=0.42$ and $\xi=0.225$, the remaining parameters of the model are re-calibrated following the procedure described in Section 2.2, except for $\eta$.

The business cycle statistics are reported in the last two columns of Table 5. Figure 11 shows the impulse response functions for education. The model's predictions are robust to $\xi$. Compared to Model1, the volatility of hours worked is slightly higher under the alternative specifications. Since the volatility is lower for high types, it is not surprising that aggregate volatility increases as the fraction of high types decreases. However, the change is very small. Nevertheless, our preferred specification remains the version with $\xi=0.58$. Since we observe differences in the time spent studying between who enroll in college and who does not, setting $\xi$ to match the fraction of high-school graduates enrolling in college seems a more sensible and less arbitrary choice.

\footnotetext{
${ }^{17}$ Source: Bureau of Labor Statistics.

${ }^{18}$ In order to use AFQT scores to calibrate $\xi$, one needs to arbitrarily choose the cut off point that distinguishes between high and low types. We are not aware of evidence in the literature suggesting an appropriate cut off point and, therefore, we chose the mean value.
} 


\section{Empirical Analysis}

\subsection{Cyclicality of time spent studying}

This section analyzes the cyclicality of education using American data from ATUS (2003-2012). The cross-sectional sample consists of 114,288 individuals who are asked to report their time allocation among several activities during a reference day. We are particularly interested in the impact of macroeconomic conditions on the time that individuals spend studying. Our goal is to test the predictions of the model regarding education.

Specifically, we estimate the time spent studying as follows:

$$
\log \left(e_{i t}\right)=\mathrm{constant}+\alpha \log \left(Z_{t}\right)+\beta X_{i t},
$$

using OLS, where $e_{i t}$ is the time spent studying during the reference day for individual $i$ in year $t^{19}, Z$ is a proxy for business-cycle fluctuations and $X$ is the vector of control variables. To be consistent with the theoretical model discussed in Section 2, we use GDP as measure of macroeconomic conditions ${ }^{20}$. The estimated coefficients are reported in Table 6 together with the standard errors. Since we express the model in log terms, the coefficient of $\ln (\mathrm{GDP})$ represents the elasticity of time spent studying with respect to output.

As shown in the table, time spent studying is counter-cyclical. Depending on the model specification, the elasticity of time spent studying with respect to output is between -0.20 and -2.5 . The baseline model in Section 2 predicts an elasticity of -0.27 . This elasticity is higher for young agents: it is -1.81 for young low types and -0.42 for young high types. Thus, the model is able to correctly predict the sign of the elasticity, but it tends to underestimate the magnitude. This result could depend on the fact that ATUS covers a short period of time and this period is known to be highly volatile because of the recent recession.

Further, ATUS does not allow to test one of the main predictions of the model: low types are more

\footnotetext{
${ }^{19}$ To be consistent with our calibration, the activity codes used in the empirical analysis are 060101 and 060301.

${ }^{20}$ The results are robust to alternative measures: unemployment rate, employment rate and industrial production. Results are available upon request.
} 
responsive than high types to macroeconomic conditions. The information on ability contained in the survey is very limited. Therefore, the next section of the paper investigates the cyclicality of education by looking at PSE enrollment from CPS. On one hand, this dataset has several advantages over ATUS. It is available for a longer period of time and it allows to distinguish between ability types. On the other hand, CPS does not include information on the time spent studying, making the quantitative comparison between the model and the data difficult. Nevertheless, since there is a correspondence between the time devoted to education and enrollment decisions, analyzing enrollment is still useful to test the qualitative predictions of the model. If economic contractions encourage PSE enrollment, the time that individuals spend studying will necessarily increase.

\subsection{Cyclicality of post-secondary enrollment}

This section analyzes the cyclicality of education using data from CPS March Supplement (19862012) ${ }^{21}$. The cross-sectional sample consists of 118,618 high-school graduates of age 16 to 24 . As largely documented in the literature, schooling decisions are affected by demographics, geography, family resources, parental education and tuition. Given this set of characteristics, we estimate the probability of being enrolled in college using a probit regression:

$$
\operatorname{Pr}\left(\text { enrolled }_{i t}=1\right)=\Psi\left(\text { constant }+\alpha X_{i t}+\beta Z_{t}\right)
$$

where enrolled $_{i t}$ is a dummy variable equal one if individual $i$ is enrolled at time $t$ and zero otherwise $^{22}, \Psi$ is the standard normal distribution function, $X$ is the vector of control variables and $Z$ is a proxy for business-cycle fluctuations. Previous studies in the literature have already attempted to analyze the relationship between enrollment and macroeconomic conditions reporting inconsistent results (e.g. Kane 1994; Edwards 1976; Betts and McFarland 1995; Méndez and Sepúlveda 2012). In the literature, the most common proxy for business cycles is unemployment. In this pa-

\footnotetext{
${ }^{21}$ Questions regarding enrollment in post-secondary education are available in CPS starting from 1986 and are only asked to individuals aged 16 to 24 .

${ }^{22} \mathrm{~A}$ person is considered to be enrolled if she is attending a full-time or part-time program in a post-secondary institution, including both 2-year and 4-year colleges.
} 
per, we mainly use GDP to be consistent with the theoretical model discussed in Section 2. However, the results are robust to different measures of business-cycle fluctuations, as discussed later in this section. The vector $X$ includes control variables that affect enrollment rates as documented in the literature.

The average marginal effects from the probit estimation are reported in Table 7 . Robust standard errors, corrected for clustering and stratification, are in parentheses ${ }^{23}$. The main variable of interest is $\ln ($ GDP), which has a negative marginal effect. A one-percent increase in GDP above trend decreases the probability of being enrolled in PSE by 1.37 percentage points. This implies that enrollment rates are counter-cyclical, which is consistent with the theoretical results. Other measures of macroeconomic conditions provide the same conclusion. In all cases, enrollment in PSE is counter-cyclical. The variables that are negatively correlated with GDP have a positive marginal effect on the likelihood of being enrolled, while the variables that are positively correlated with GDP have a negative impact.

\subsection{The cyclicality of enrollment by ability type}

The sample has also been divided into two groups in order to distinguish between high and low types. Parental education is used as proxy for ability ${ }^{24}$. This is common in the economics of education literature and reflects the fact that ability is both inherited and created. Besides genetics, ability greatly depends on early human capital investments made by parents on behalf of their children, family income and the parental environment. For a review of the empirical and theoretical studies on this topic, see Cunha et al. (2006) and Carneiro and Heckman (2003). For these reasons, parental education is a strong predictor of an individual's educational achievement and

\footnotetext{
${ }^{23}$ The information about clustering and stratification variables in CPS is not released to the public. Further, replicate weights are not available before 2005. Therefore, in order to correct the standard errors, we use proxies for clustering and stratification variables. In particular, we define the strata to be the state in which the individual lives. This is the smallest geographic unit that can be identified in CPS (public version). Households, instead, are used to identify clusters. As robustness check, we compare the standard errors from the estimation with replicate weights and the one with our proxies for clustering and stratification variables for the period 2005-2011. Results show that there is no significant difference in the estimated standard errors. See Davern et al. (2006) and Davern et al. (2007) for more details.

${ }^{24}$ Parental education is also available in ATUS. However, since it is only reported for few individuals, the sample size does not allow to study the cyclicality of time spent studying separately for high and low types.
} 
it is often used as proxy for ability. In particular, high types have been arbitrarily defined as those individuals whose parents studied at least one year at any post-secondary institution. Low types have been defined as those individuals whose parents have at most a high-school diploma. Independently of the business-cycle measure, the impact is greater for low types compared to high types as shown in Table 7. A one-percent increase in GDP above trend decreases the probability of being enrolled by 0.66 percentage points for high types and by 1.94 percentage points for low types. This is consistent with the predictions of the theoretical model: the response to macroeconomic conditions is stronger for low-productivity individuals.

In Table 9 we check the robustness of the results by changing the criterion used to define high and low types. The first column reports the results using the original classification. In the second column, instead, high types are defined as those individuals whose parents have obtained at least a Bachelor's degree. Finally, in the third column, high types are defined as those individuals whose parents have at least completed grade 12. Results suggest that the effect of GDP on enrollment decisions is always stronger for low types. Further, the magnitude of the effect depends on the classification of high and low types in a way that is consistent with the theoretical predictions from the model.

\section{Conclusions}

This paper shows that during an economic crisis the education sector helps the economy to react to the shock. The decrease in wages reduces the opportunity cost of education, while the decrease in the rental rate of physical capital decreases its marginal product. Therefore, agents invest more in human capital because it is cheaper (therefore more efficient) to do so. Education is less expensive and human capital is more attractive than physical capital. This is especially true for young and low-productivity agents. Since both are less productive at work, they are more likely to substitute work with schooling. These results are empirically confirmed using US data: a onepercent increase in GDP above trend decreases the probability of being enrolled by 1.37 percentage points. The marginal effect is higher for low types compared to high types. 
Regarding hours worked volatility, we showed that human capital accumulation is necessary to produce a U-shaped volatility profile. Further, models with heterogeneity by productivity within ages can produce a higher volatility and a better volatility profile. In this case, the presence of low types is particularly important because they reduce hours worked more compared to high types. As a result, aggregate volatility is higher. Finally, introducing schooling in the model reduces the volatility of hours worked. This is in contrast with previous papers in the RBC literature (e.g. Einarsson and Marquis 1998 and DeJong and Ingram 2001). Since education is an alternative to work, introducing schooling increases the volatility in a baseline RBC model. This result no longer holds in a life-cycle setting because the benefit of education differs among agents. As a result, not everyone in the economy considers education as a valid alternative to work. 


\section{Figures}

Figure 1: Profiles for time spent studying for different levels of $\delta_{h}$

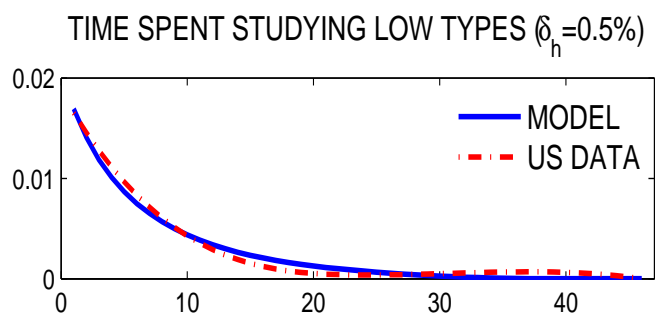

TIME SPENT STUDYING HIGH TYPES $\left(\delta_{h}=0.5 \%\right)$

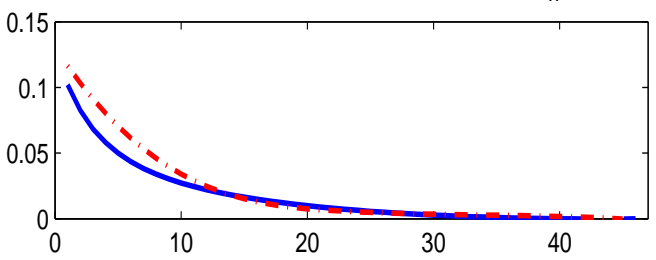

TIME SPENT STUDYING LOW TYPES $\left(\delta_{\mathrm{h}}=1.5 \%\right)$

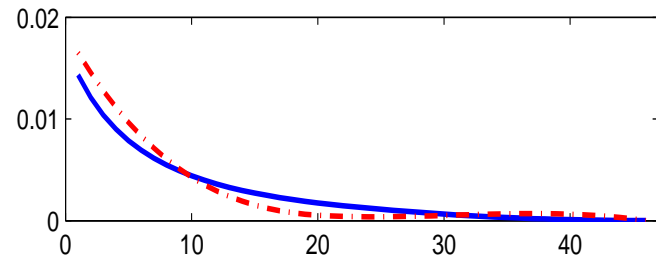

TIME SPENT STUDYING HIGH TYPES $\left(\delta_{h}=1.5 \%\right)$

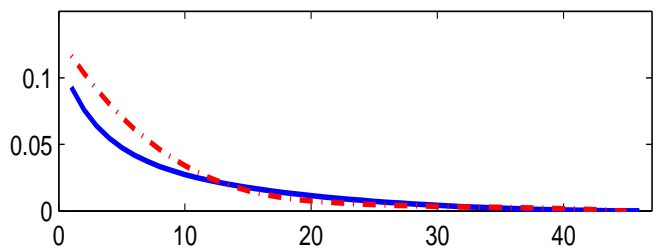

TIME SPENT STUDYING LOW TYPES $\left(\delta_{h}=2 \%\right)$

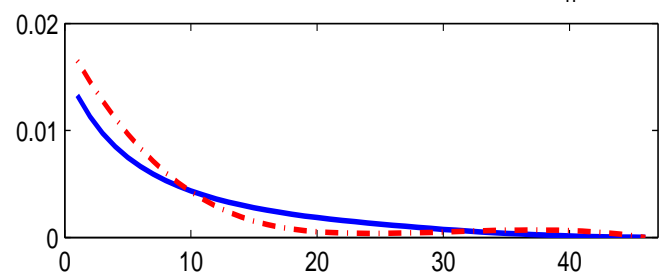

TIME SPENT STUDYING HIGH TYPES $\left(\delta_{h}=2 \%\right)$

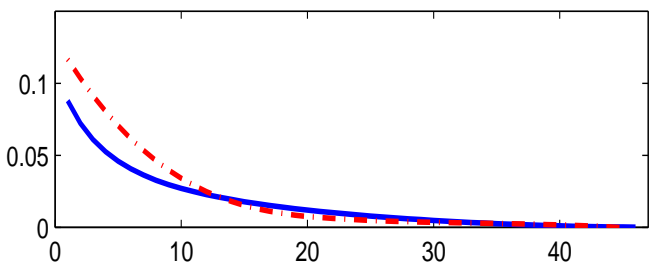

TIME SPENT STUDYING LOW TYPES $\left(\delta_{h}=4 \%\right)$

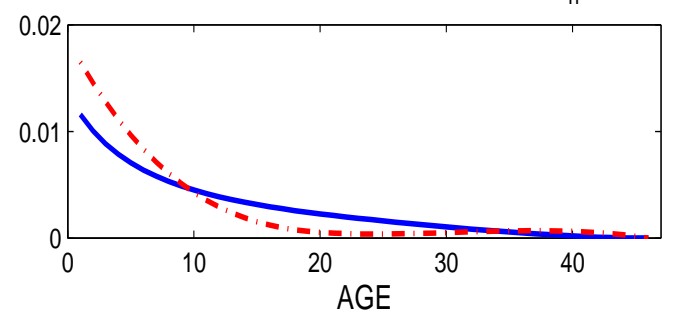

TIME SPENT STUDYING HIGH TYPES $\left(\delta_{h}=4 \%\right)$

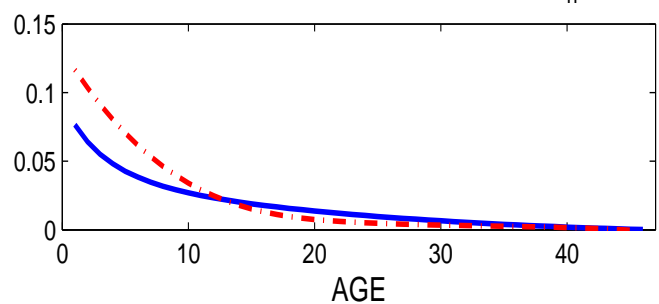


Figure 2: Estimated efficiency weights and productivity sequences during the working life
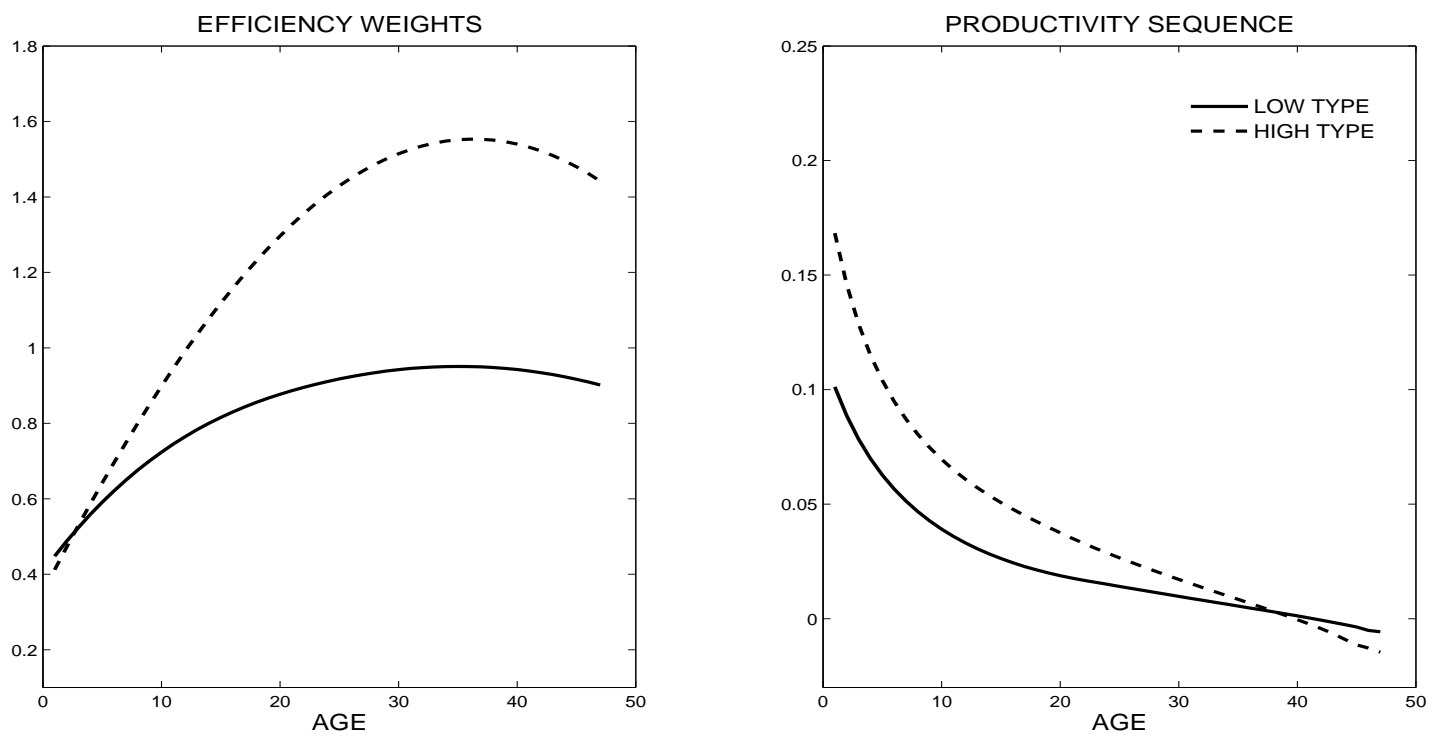

Figure 3: Steady-state values by age and type
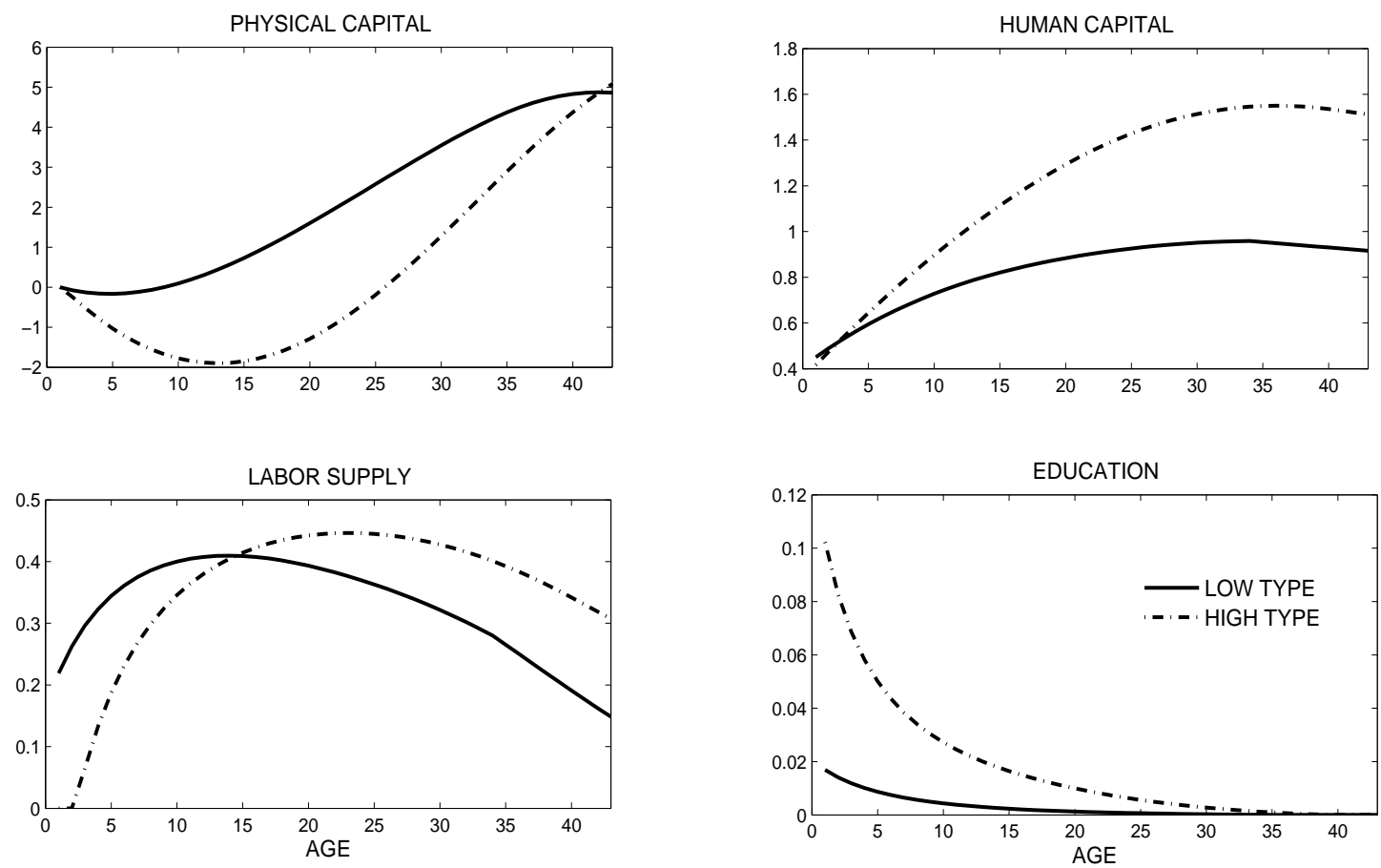
Figure 4: Life-cycle profiles

TIME SPENT STUDYING LOW TYPES (e $\left.e_{s}\right)$
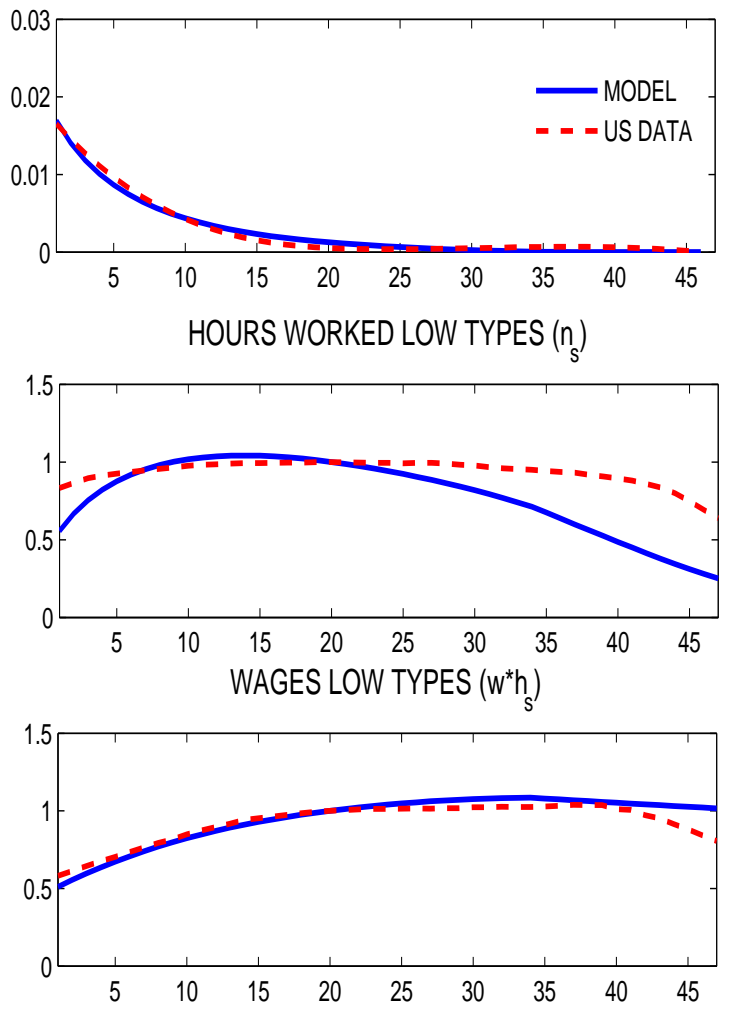

HUMAN CAPITAL LOW TYPES $\left(\mathrm{h}_{\mathrm{s}}\right)$

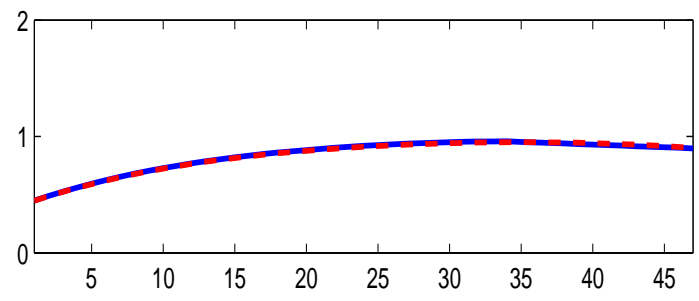

TIME SPENT STUDYING HIGH TYPES $\left(e_{s}\right)$
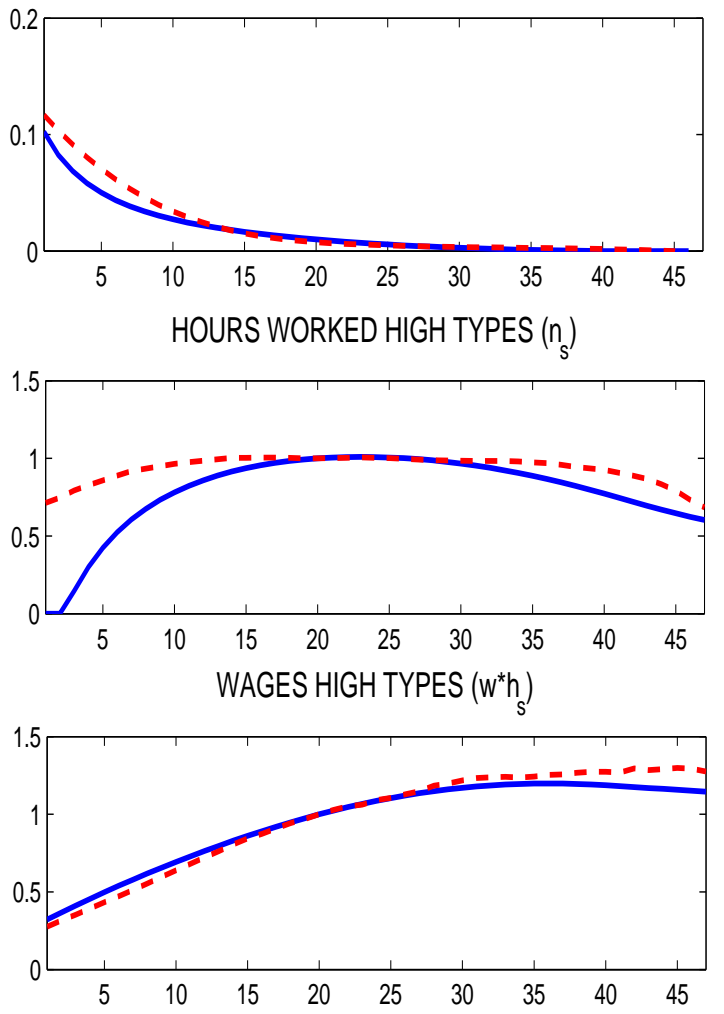

HUMAN CAPITAL HIGH TYPES $\left(h_{\mathrm{s}}\right)$

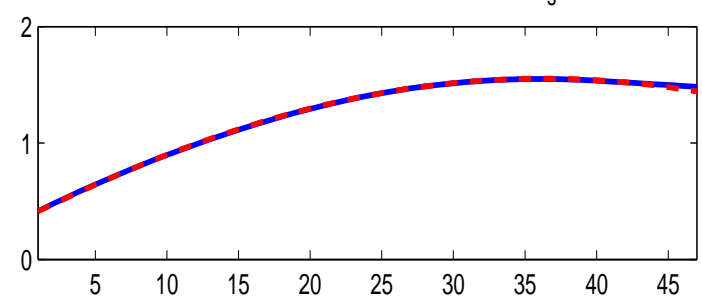


Figure 5: Impulse response functions for the aggregate economy
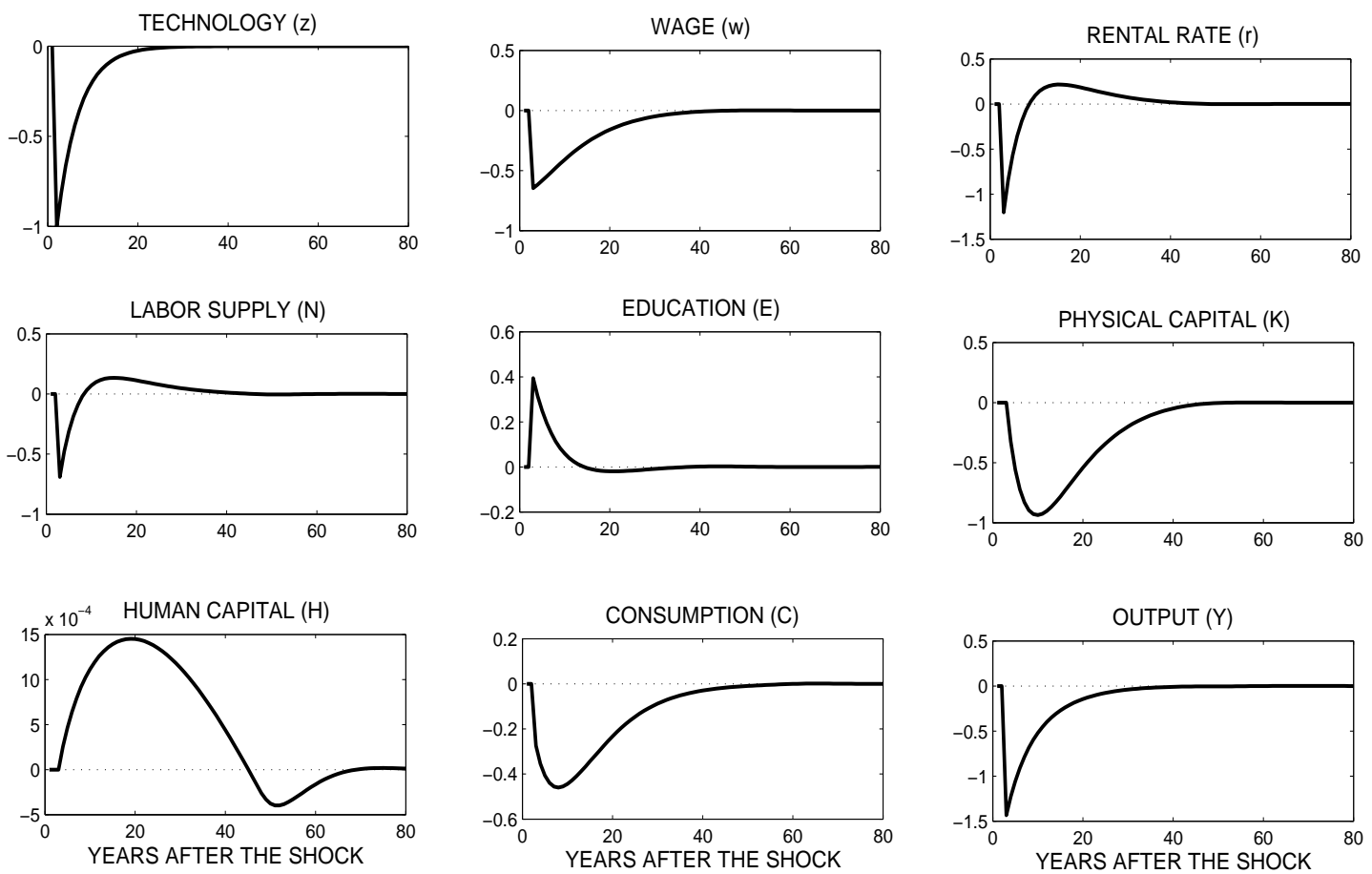

Figure 6: Impulse response functions by ability type and age group
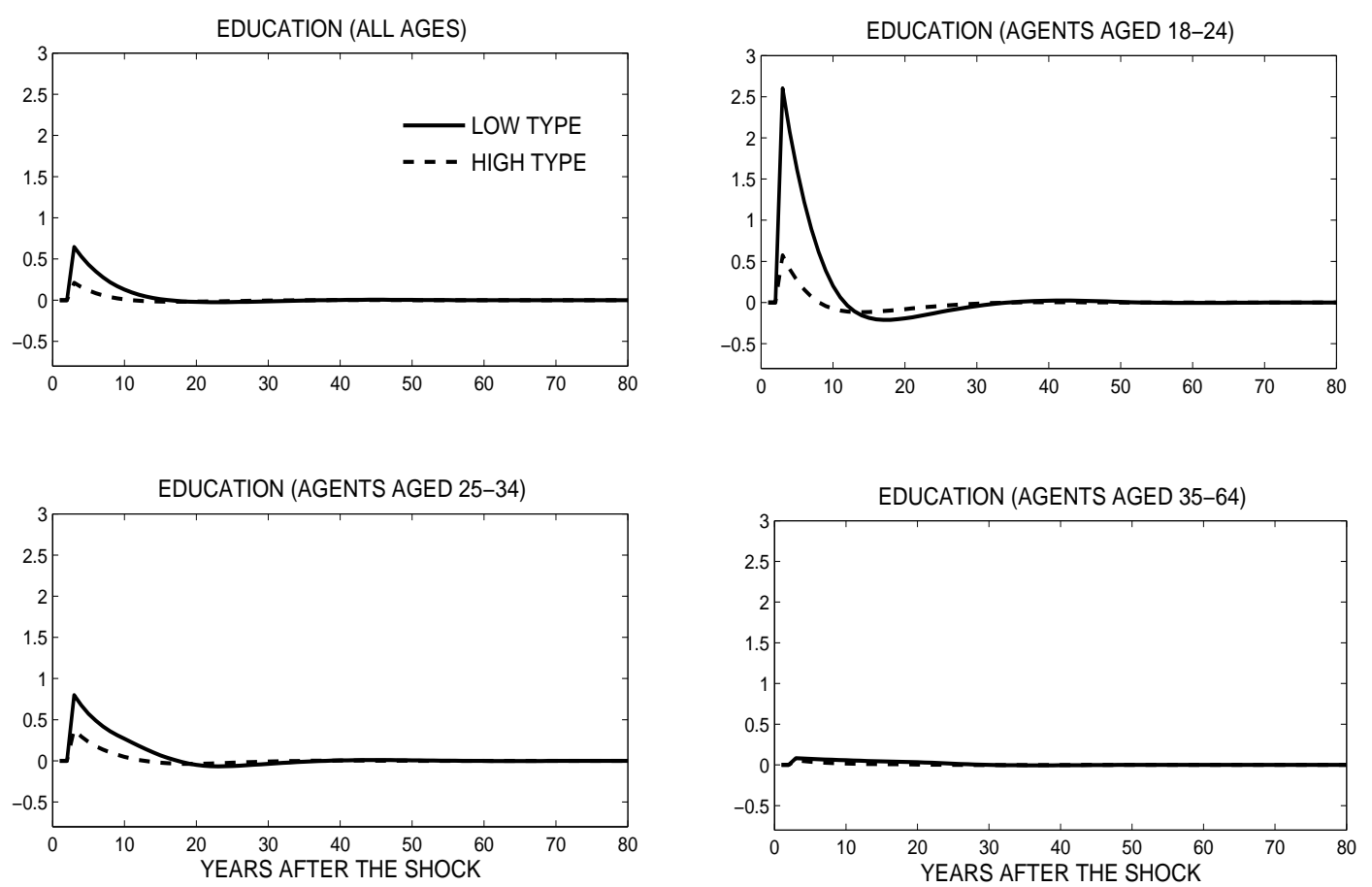
Figure 7: Hours worked volatility by age group
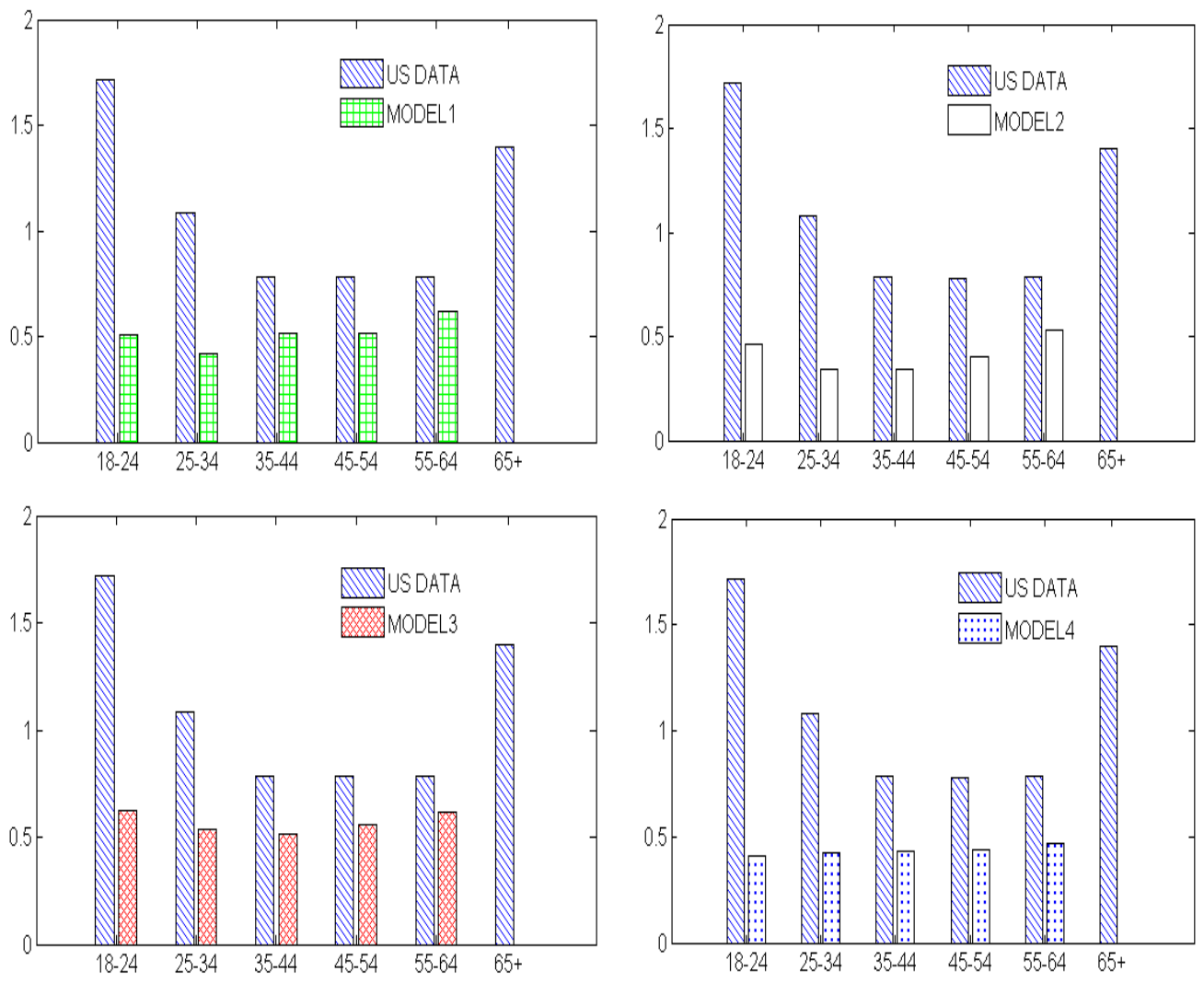
Figure 8: Impulse response functions by ability type and age group: model with $\phi_{\text {high }}=\phi_{\text {low }}$
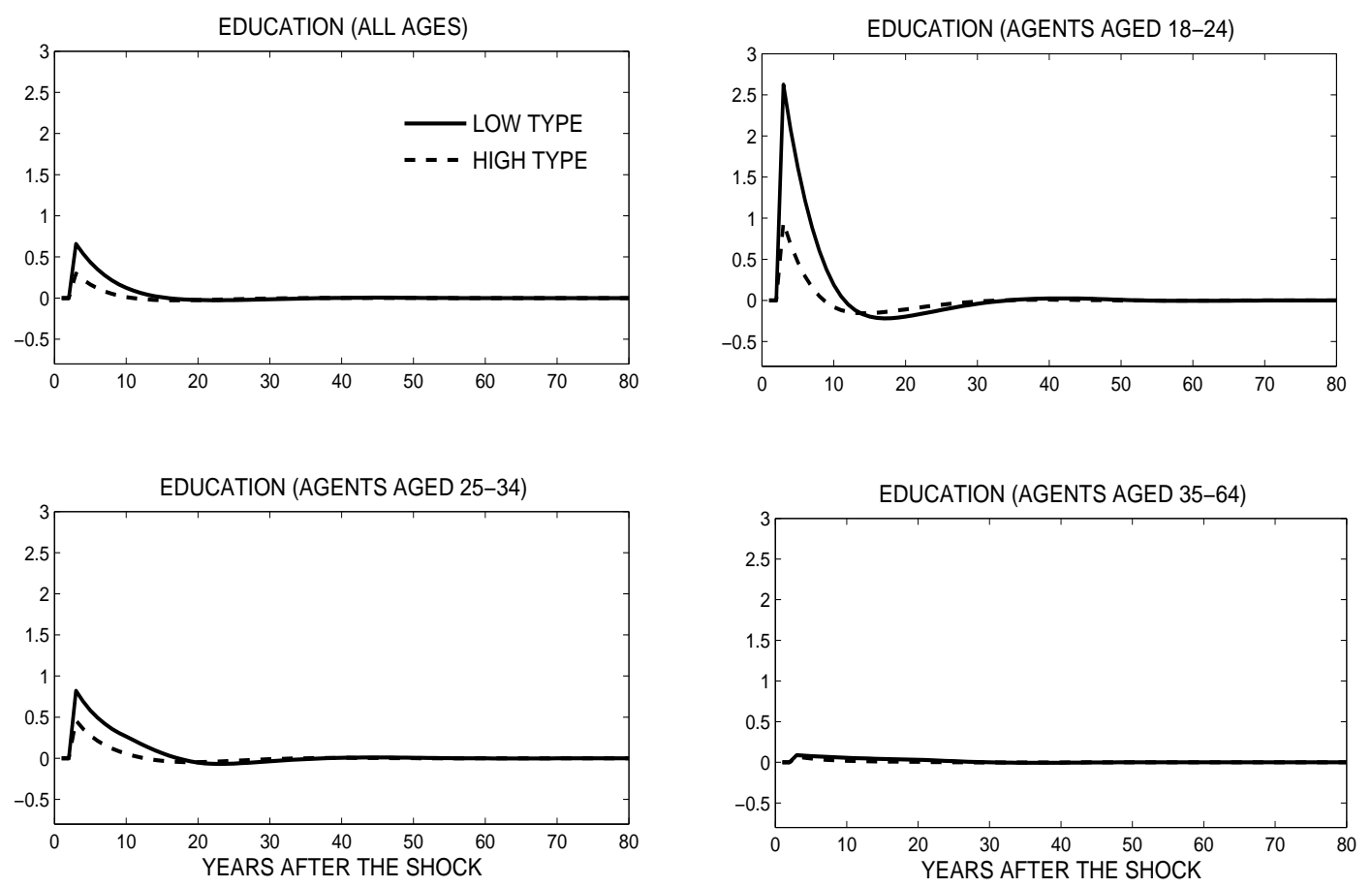
Figure 9: Life-cycle profiles: model with $\phi_{\text {high }}=\phi_{\text {low }}$

TIME SPENT STUDYING (e) $\mathrm{e}_{\mathrm{s}}$ : LOW TYPES

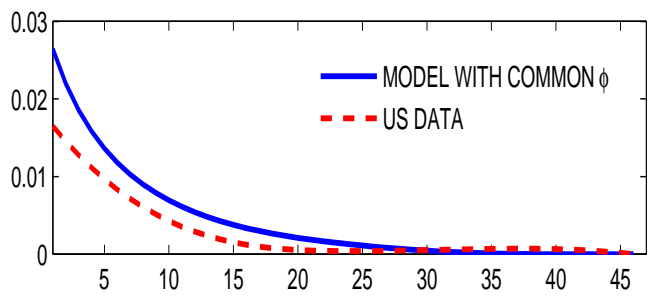

HOURS WORKED $\left(n_{s}\right)$ : LOW TYPES

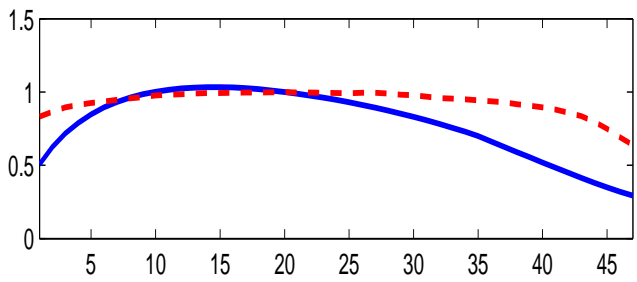

EFFICIENCY WAGES (wh): LOW TYPES

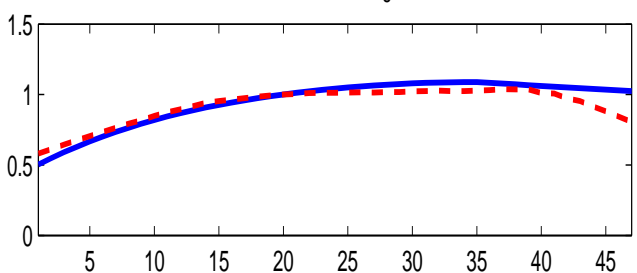

HUMAN CAPITAL (h): LOW TYPES

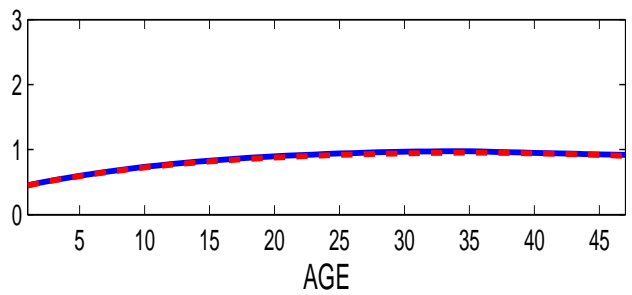

TIME SPENT STUDYING (es): HIGH TYPES

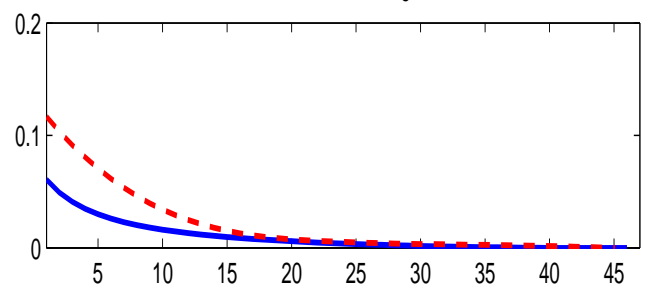

HOURS WORKED ( $n_{s}$ : HIGH TYPES

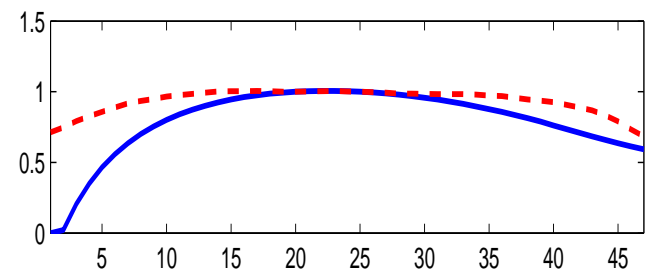

EFFICIENCY WAGES (wh): HIGH TYPES

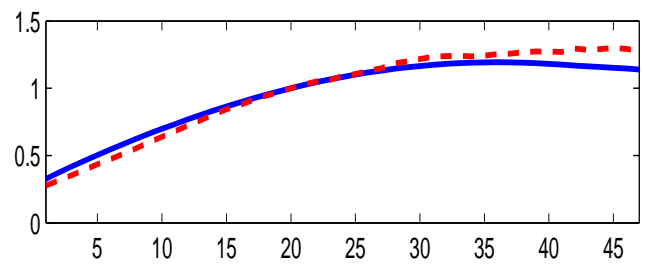

HUMAN CAPITAL (h): HIGH TYPES

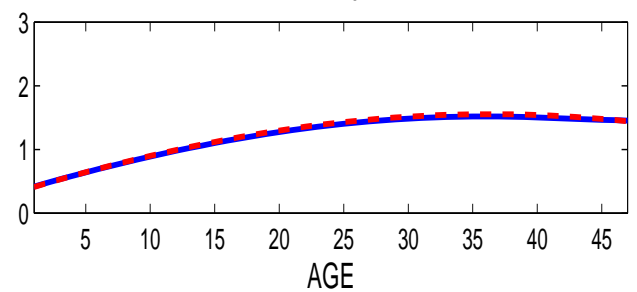


Figure 10: Impulse response functions by ability type and age group: model with endogenous retirement
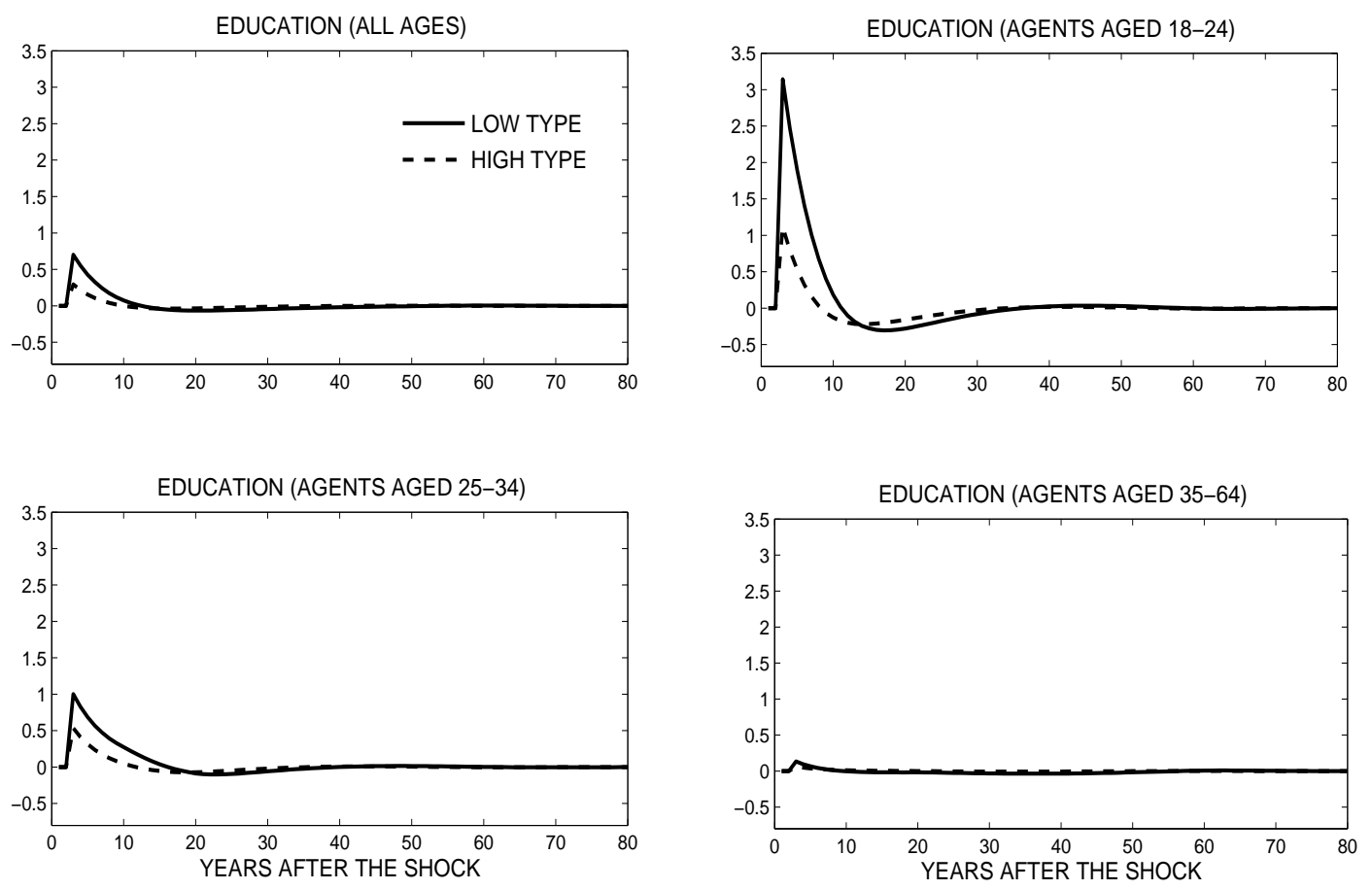
Figure 11: Impulse response functions by ability type and age group: experiment with $\xi$
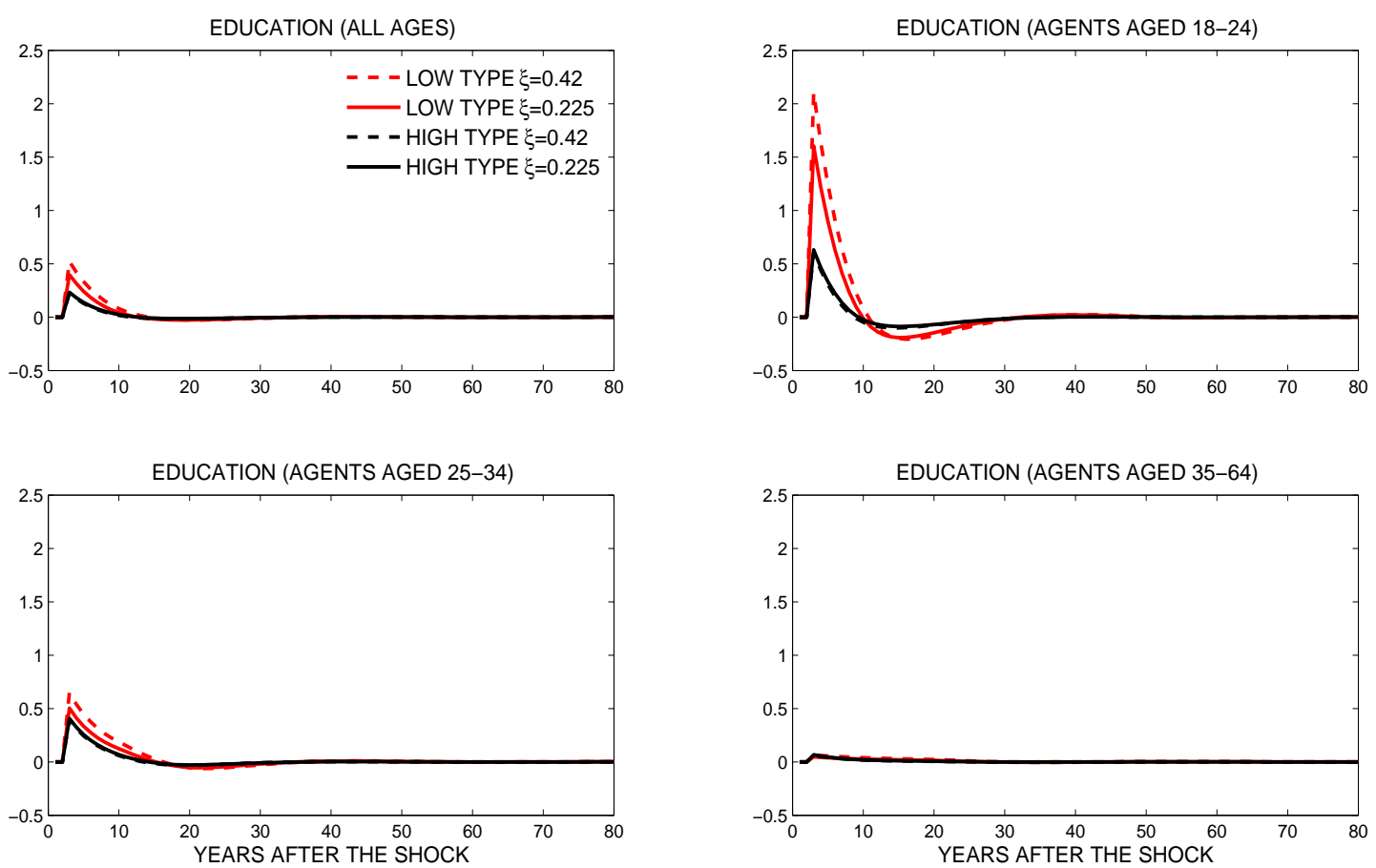


\section{Tables}

Table 1: Calibration of the model

\begin{tabular}{clccc}
\hline \hline Parameter & $\begin{array}{l}\text { Calibrated } \\
\text { value }\end{array}$ & Set to target & $\begin{array}{c}\text { Value from } \\
\text { US data }\end{array}$ & $\begin{array}{c}\text { Value from } \\
\text { the model }\end{array}$ \\
\hline$S_{\text {max }}$ & 60 & $\begin{array}{c}\text { life expectancy at age } \\
18\end{array}$ & 58.99 & 58.47 \\
$S_{r}$ & 47 & $\begin{array}{c}\text { ratio of retired people } \\
\text { to active population }\end{array}$ & $21.6 \%$ & $20.7 \%$ \\
$\gamma$ & 1.85 & $N^{*}$ & 0.33 & 0.33 \\
$\eta$ & 1.075 & $\sigma_{Y}$ & 1.36 & 1.36 \\
$\delta$ & 0.06 & $\begin{array}{c}\text { average annual real } \\
\text { interest rate }\end{array}$ & $6 \%$ & $6 \%$ \\
$\beta$ & 0.969 & $\begin{array}{c}\text { average physical } \\
\text { capital to output ratio }\end{array}$ & 3 & 3 \\
$\phi_{\text {high }}$ & 0.057 & $E_{\text {high }}^{*}$ & 0.017 & 0.017 \\
$\phi_{\text {low }}$ & 0.023 & $E_{\text {low }}^{*}$ & 0.003 & 0.003 \\
\hline
\end{tabular}

Table 2: Steady-state aggregate values

\begin{tabular}{lccccccc}
\hline \hline Aggregate values: & $C^{*}$ & $N^{*}$ & $H^{*}$ & $K^{*}$ & $Y^{*}$ & $w^{*}$ & $r^{*}$ \\
& 0.47 & 0.33 & 1.31 & 1.71 & 0.57 & 1.19 & 0.12 \\
\hline Household: & & $N^{*}$ & $K^{*}$ & $H^{*}$ & $E^{*}$ \\
high type & & 0.35 & 1.23 & 1.52 & 0.017 \\
low type & & 0.31 & 2.38 & 1.01 & 0.003 \\
\hline
\end{tabular}


Table 3: Business cycle statistics

\begin{tabular}{|c|c|c|c|c|c|c|c|c|c|c|}
\hline \multirow[t]{2}{*}{$X$} & \multicolumn{5}{|c|}{$\sigma_{X}$} & \multicolumn{5}{|c|}{$\operatorname{corr}(X, Y)$} \\
\hline & DATA & MODEL1 & MODEL2 & MODEL3 & MODEL4 & Data & MODEL1 & MODEL2 & MODEL3 & MODEL4 \\
\hline$Y$ & 1.36 & 1.36 & 1.30 & 1.34 & 1.24 & 1 & 1 & 1 & 1 & 1 \\
\hline C & 1.12 & 0.28 & 0.37 & 0.28 & 0.36 & 0.91 & 0.97 & 0.93 & 0.87 & 0.93 \\
\hline$I$ & 6.72 & 6.06 & 4.05 & 6.27 & 5.45 & 0.92 & 0.98 & 0.92 & 0.97 & 0.99 \\
\hline$N$ & 1.29 & 0.66 & 0.54 & 0.75 & 0.54 & 0.85 & 0.99 & 0.99 & 0.98 & 0.99 \\
\hline$E$ & - & 0.37 & 0.31 & - & - & - & -0.99 & -0.99 & - & - \\
\hline$N_{\text {low }}$ & $1.54 *$ & 1.13 & - & 1.11 & - & $0.85^{*}$ & 0.99 & - & 0.99 & - \\
\hline$N_{\text {high }}$ & $0.66^{*}$ & 0.37 & - & 0.47 & - & $0.77 *$ & 0.98 & - & 0.99 & - \\
\hline$E_{\text {low }}$ & - & 0.61 & - & - & - & - & -0.99 & - & - & - \\
\hline$E_{\text {high }}$ & - & 0.21 & - & - & - & - & -0.99 & - & - & - \\
\hline$N(18-24)$ & 2.33 & 0.69 & 0.60 & 0.84 & 0.51 & 0.75 & 0.99 & 0.99 & 0.97 & 0.99 \\
\hline$N(25-34)$ & 1.47 & 0.57 & 0.45 & 0.72 & 0.53 & 0.81 & 0.88 & 0.98 & 0.97 & 0.99 \\
\hline$N(35-44)$ & 1.07 & 0.70 & 0.44 & 0.69 & 0.54 & 0.87 & 0.82 & 0.98 & 0.89 & 0.99 \\
\hline$N(45-54)$ & 1.06 & 0.70 & 0.52 & 0.74 & 0.55 & 0.81 & 0.97 & 0.99 & 0.97 & 0.99 \\
\hline$N(55-64)$ & 1.07 & 0.85 & 0.69 & 0.83 & 0.59 & 0.78 & 0.96 & 0.99 & 0.98 & 0.99 \\
\hline$N_{\text {low }}(18-24)$ & $2.66^{*}$ & 1.22 & - & 1.19 & - & $0.73 *$ & 0.99 & - & 0.99 & - \\
\hline$N_{\text {low }}(25-34)$ & $1.84^{*}$ & 1.03 & - & 1.01 & - & $0.84^{*}$ & 0.99 & - & 0.99 & - \\
\hline$N_{\text {low }}(35-44)$ & $1.49 *$ & 1.04 & - & 1.03 & - & $0.84 *$ & 0.99 & - & 0.99 & - \\
\hline$N_{\text {low }}(45-54)$ & $1.30 *$ & 1.13 & - & 1.12 & - & $0.84 *$ & 0.99 & - & 0.99 & - \\
\hline$N_{\text {low }}(55-64)$ & $1.24 *$ & 1.24 & - & 1.22 & - & $0.81 *$ & 0.99 & - & 0.99 & - \\
\hline$N_{h i g h}(18-24)$ & $1.62 *$ & 0.38 & - & 0.53 & - & $0.59 *$ & 0.99 & - & 0.99 & - \\
\hline$N_{h i g h}(25-34)$ & $0.80^{*}$ & 0.38 & - & 0.44 & - & $0.75^{*}$ & 0.98 & - & 0.99 & - \\
\hline$N_{\text {high }}(35-44)$ & $0.64 *$ & 0.33 & - & 0.40 & - & $0.60 *$ & 0.98 & - & 0.99 & - \\
\hline$N_{h i g h}(45-54)$ & $0.72 *$ & 0.35 & - & 0.44 & - & $0.57 *$ & 0.98 & - & 0.99 & - \\
\hline$N_{h i g h}(55-64)$ & $1.01 *$ & 0.41 & - & 0.55 & - & $0.51 *$ & 0.98 & - & 0.99 & - \\
\hline
\end{tabular}

$\mathrm{Y}$ is output, $\mathrm{C}$ is consumption, I is investment, $\mathrm{N}$ is labor supply, $N_{\text {low }}$ is labor supply for low types, $N_{\text {high }}$ is labor supply for high types, $E_{\text {low }}$ is education for low types and $E_{\text {high }}$ is education for high types.

MODEL1: baseline model

MODEL2: one ability type

MODEL3: exogenous human capital

MODEL4: no human capital accumulation

* Refers to time period 1992-2012: hours worked for the two ability types can be estimated starting from 1992 only because the question about education achievement in CPS was changed in 1992. Thus, in order to have a definition of ability type consistent over time, $N_{\text {low }}$ and $N_{h i g h}$ have been estimated using data from 1992 to 2012 only. 
Table 4: Calibration of the alternative specifications

\begin{tabular}{|c|c|c|c|c|c|}
\hline Specification & Parameter & $\begin{array}{c}\text { Calibrated } \\
\text { value }\end{array}$ & $\begin{array}{l}\text { Set to } \\
\text { target }\end{array}$ & $\begin{array}{l}\text { Value from } \\
\text { US data }\end{array}$ & $\begin{array}{l}\text { Value from } \\
\text { the model }\end{array}$ \\
\hline \multirow{3}{*}{ Model2 } & $\gamma$ & 1.89 & $N^{*}$ & 0.33 & 0.33 \\
\hline & $\beta$ & 0.9679 & $K^{*} / Y^{*}$ & 3 & 3 \\
\hline & $\phi$ & 0.037 & $E^{*}$ & 0.008 & 0.008 \\
\hline \multirow[t]{2}{*}{ Model3 } & $\gamma$ & 1.86 & $N^{*}$ & 0.33 & 0.33 \\
\hline & $\beta$ & 0.968 & $K^{*} / Y^{*}$ & 3 & 3 \\
\hline \multirow[t]{2}{*}{ Model4 } & $\gamma$ & 1.55 & $N^{*}$ & 0.33 & 0.33 \\
\hline & $\beta$ & 1.04 & $K^{*} / Y^{*}$ & 3 & 3 \\
\hline \multirow[t]{3}{*}{ Common $\phi$} & $\gamma$ & 1.85 & $N^{*}$ & 0.33 & 0.33 \\
\hline & $\beta$ & 0.968 & $K^{*} / Y^{*}$ & 3 & 3 \\
\hline & $\phi$ & 0.035 & $E^{*}$ & 0.008 & 0.008 \\
\hline \multirow[t]{4}{*}{ End. ret. } & $\gamma$ & 1.50 & $N^{*}$ & 0.33 & 0.33 \\
\hline & $\beta$ & 0.972 & $K^{*} / Y^{*}$ & 3 & 3 \\
\hline & $\phi_{\text {high }}$ & 0.058 & $E_{\text {high }}^{*}$ & 0.017 & 0.017 \\
\hline & $\phi_{\text {low }}$ & 0.02 & $E_{\text {low }}^{*}$ & 0.003 & 0.003 \\
\hline \multirow[t]{4}{*}{$\xi=0.42$} & $\gamma$ & 1.83 & $N^{*}$ & 0.33 & 0.33 \\
\hline & $\beta$ & 0.9675 & $K^{*} / Y^{*}$ & 3 & 3 \\
\hline & $\phi_{\text {high }}$ & 0.057 & $E_{\text {high }}^{*}$ & 0.017 & 0.017 \\
\hline & $\phi_{l o w}$ & 0.022 & $E_{l o w}^{*}$ & 0.003 & 0.003 \\
\hline \multirow[t]{4}{*}{$\xi=0.225$} & $\gamma$ & 1.88 & $N^{*}$ & 0.33 & 0.33 \\
\hline & $\beta$ & 0.966 & $K^{*} / Y^{*}$ & 3 & 3 \\
\hline & $\phi_{\text {high }}$ & 0.055 & $E_{\text {high }}^{*}$ & 0.017 & 0.017 \\
\hline & $\phi_{l o w}$ & 0.022 & $E_{\text {low }}^{*}$ & 0.003 & 0.003 \\
\hline
\end{tabular}

The remaining parameters are the same as in Table 1. 
Table 5: Business cycle statistics - sensitivity analysis

\begin{tabular}{|c|c|c|c|c|c|c|c|c|c|c|}
\hline \multirow[t]{2}{*}{$X$} & \multicolumn{5}{|c|}{$\sigma_{X}$} & \multicolumn{5}{|c|}{$\operatorname{corr}(X, Y)$} \\
\hline & MODEL1 & $\phi_{H}=\phi_{L}$ & END.RET. & $\xi=0.42$ & $\xi=0.225$ & MODEL1 & $\phi_{H}=\phi_{L}$ & END.RET. & $\xi=0.42$ & $\xi=0.225$ \\
\hline$Y$ & 1.36 & 1.33 & 1.40 & 1.33 & 1.28 & 1 & 1 & 1 & 1 & 1 \\
\hline C & 0.28 & 0.31 & 0.30 & 0.24 & 0.28 & 0.97 & 0.74 & 0.96 & 0.93 & 0.90 \\
\hline$I$ & 6.06 & 6.71 & 5.45 & 6.49 & 6.64 & 0.98 & 0.93 & 0.99 & 0.98 & 0.93 \\
\hline$N$ & 0.66 & 0.78 & 0.76 & 0.69 & 0.67 & 0.99 & 0.94 & 0.99 & 0.99 & 0.97 \\
\hline$E$ & 0.37 & 0.43 & 0.45 & 0.37 & 0.34 & -0.99 & -0.99 & -0.99 & -0.99 & -0.99 \\
\hline$N_{\text {low }}$ & 1.13 & 1.11 & 1.18 & 0.94 & 0.76 & 0.99 & 0.99 & 0.99 & 0.99 & 0.99 \\
\hline$N_{\text {high }}$ & 0.37 & 0.48 & 0.47 & 0.37 & 0.36 & 0.98 & 0.98 & 0.98 & 0.98 & 0.96 \\
\hline$E_{\text {low }}$ & 0.61 & 0.62 & 0.67 & 0.49 & 0.38 & -0.99 & -0.99 & -0.99 & -0.99 & -0.99 \\
\hline$E_{\text {high }}$ & 0.21 & 0.29 & 0.29 & 0.22 & 0.22 & -0.99 & -0.99 & -0.99 & -0.99 & -0.98 \\
\hline$N(18-24)$ & 0.69 & 0.90 & 0.75 & 0.74 & 0.72 & 0.99 & 0.95 & 0.99 & 0.99 & 0.97 \\
\hline$N(25-34)$ & 0.57 & 0.82 & 0.61 & 0.63 & 0.65 & 0.88 & 0.91 & 0.99 & 0.99 & 0.94 \\
\hline$N(35-44)$ & 0.70 & 1.03 & 0.65 & 0.61 & 0.60 & 0.82 & 0.58 & 0.98 & 0.99 & 0.98 \\
\hline$N(45-54)$ & 0.70 & 0.80 & 0.75 & 0.70 & 0.63 & 0.97 & 0.90 & 0.99 & 0.98 & 0.98 \\
\hline$N(55-64)$ & 0.85 & 0.85 & 0.92 & 0.77 & 0.77 & 0.96 & 0.92 & 0.99 & 0.98 & 0.97 \\
\hline$N_{\text {low }}(18-24)$ & 1.22 & 1.22 & 1.14 & 1.00 & 0.81 & 0.99 & 0.99 & 0.99 & 0.99 & 0.99 \\
\hline$N_{\text {low }}(25-34)$ & 1.03 & 1.01 & 0.98 & 0.84 & 0.67 & 0.99 & 0.99 & 0.99 & 0.99 & 0.99 \\
\hline$N_{\text {low }}(35-44)$ & 1.04 & 1.02 & 1.04 & 0.86 & 0.68 & 0.99 & 0.99 & 0.99 & 0.99 & 0.99 \\
\hline$N_{\text {low }}(45-54)$ & 1.13 & 1.10 & 1.20 & 0.94 & 0.76 & 0.99 & 0.99 & 0.99 & 0.99 & 0.99 \\
\hline$N_{\text {low }}(55-64)$ & 1.24 & 1.20 & 1.40 & 1.05 & 0.88 & 0.99 & 0.99 & 0.99 & 0.99 & 0.99 \\
\hline$N_{\text {high }}(18-24)$ & 0.38 & 0.56 & 0.51 & 0.40 & 0.42 & 0.99 & 0.99 & 0.99 & 0.99 & 0.97 \\
\hline$N_{\text {high }}(25-34)$ & 0.38 & 0.46 & 0.41 & 0.40 & 0.41 & 0.98 & 0.98 & 0.98 & 0.98 & 0.96 \\
\hline$N_{\text {high }}(35-44)$ & 0.33 & 0.41 & 0.38 & 0.33 & 0.34 & 0.98 & 0.98 & 0.98 & 0.98 & 0.96 \\
\hline$N_{h i g h}(45-54)$ & 0.35 & 0.45 & 0.43 & 0.33 & 0.32 & 0.98 & 0.98 & 0.98 & 0.98 & 0.95 \\
\hline$N_{\text {high }}(55-64)$ & 0.41 & 0.54 & 0.56 & 0.37 & 0.33 & 0.98 & 0.98 & 0.98 & 0.97 & 0.94 \\
\hline
\end{tabular}

$\mathrm{Y}$ is output, $\mathrm{C}$ is consumption, I is investment, $\mathrm{N}$ is labor supply, $\mathrm{E}$ is education time, $N_{\text {low }}$ is labor supply for low types and $N_{h i g h}$ is labor supply for high types, $E_{\text {low }}$ is education for low types and $E_{\text {high }}$ is education for high types. $\phi_{L}$ stands for $\phi_{\text {low }}, \phi_{H}$ stands for $\phi_{\text {high }}$. 
Table 6: Estimated coefficients of $\ln (\mathrm{GDP})$

\begin{tabular}{|c|c|c|c|c|c|c|c|c|}
\hline \multicolumn{9}{|l|}{ Dependent variable: $\ln (\mathrm{e})$} \\
\hline & $\begin{array}{c}\text { Coeff. } \\
\text { (Std. err.) }\end{array}$ & $\begin{array}{c}\text { Coeff. } \\
\text { (Std. err.) }\end{array}$ & $\begin{array}{c}\text { Coeff. } \\
\text { (Std. err.) }\end{array}$ & $\begin{array}{c}\text { Coeff. } \\
\text { (Std. err.) }\end{array}$ & $\begin{array}{c}\text { Coeff. } \\
\text { (Std. err.) }\end{array}$ & $\begin{array}{c}\text { Coeff. } \\
\text { (Std. err.) }\end{array}$ & $\begin{array}{c}\text { Coeff. } \\
\text { (Std. err.) }\end{array}$ & $\begin{array}{c}\text { Coeff. } \\
\text { (Std. err.) }\end{array}$ \\
\hline $\ln (\mathrm{GDP})$ & $\begin{array}{c}-0.20 * * * \\
(0.08)\end{array}$ & $\begin{array}{c}-0.23 * * * \\
(0.07)\end{array}$ & $\begin{array}{c}-1.99 * * * \\
(0.36)\end{array}$ & $\begin{array}{c}-1.88 * * * \\
(0.39)\end{array}$ & $\begin{array}{c}-1.54 * * * \\
(0.40)\end{array}$ & $\begin{array}{c}-1.40 * * * \\
(0.40)\end{array}$ & $\begin{array}{c}-1.97 * * * \\
(0.54)\end{array}$ & $\begin{array}{c}-2.51 * * * \\
(0.62)\end{array}$ \\
\hline \multicolumn{9}{|l|}{ Linear time trend } \\
\hline \multicolumn{9}{|l|}{ Quadratic trend } \\
\hline \multicolumn{9}{|l|}{ Cubic trend } \\
\hline State dummies & & $\checkmark$ & $\checkmark$ & $\sqrt{ }$ & $\sqrt{ }$ & $\sqrt{ }$ & $\checkmark$ & $\sqrt{ }$ \\
\hline Demographic variables & & $\sqrt{ }$ & $\checkmark$ & $\sqrt{ }$ & $\sqrt{ }$ & $\sqrt{ }$ & $\sqrt{ }$ & $\sqrt{ }$ \\
\hline Work & & & & $\sqrt{ }$ & & $\sqrt{ }$ & $\sqrt{ }$ & $\sqrt{ }$ \\
\hline Educational attainment & & & & $\sqrt{ }$ & & $\sqrt{ }$ & $\sqrt{ }$ & $\sqrt{ }$ \\
\hline Tuition & & & $\checkmark$ & $\checkmark$ & $\checkmark$ & $\checkmark$ & $\checkmark$ & $\sqrt{ }$ \\
\hline $\mathrm{N}$ & 114,288 & 114,288 & 114,288 & 114,288 & 114,288 & 114,288 & 114,288 & 114,288 \\
\hline F-stat & 7.19 & 90.26 & 89.15 & 95.14 & 88.40 & 94.41 & 93.02 & 91.68 \\
\hline
\end{tabular}

Standard errors are reported in brackets. *** $\mathrm{p}<0.01, * * \mathrm{p}<0.05, * \mathrm{p}<0.1$.

Demographic variables include age, age ${ }^{2}$, gender, ethnicity and marital status. Work is a dummy indicating whether the respondent works, tuition is aggregate annual tuition at the national level. These results are robust to the inclusion of other control variables such as family background variables. The full set of results is available upon request. 
Table 7: Average marginal effect of $Z_{t}$ on the likelihood of being enrolled

\begin{tabular}{lcccc}
\hline \hline Dependent variable: college enrollment $(=1$ if enrolled in PSE, =0 otherwise) \\
\hline & $\ln (\mathrm{GDP})$ & $\begin{array}{c}\text { National un- } \\
\text { employment } \\
\text { rate }\end{array}$ & $\begin{array}{c}\text { Index of } \\
\text { industrial } \\
\text { production }\end{array}$ & $\begin{array}{c}\text { Employment } \\
\text {-population } \\
\text { ratio }\end{array}$ \\
\hline Whole sample & $-1.365^{* * *}$ & $0.044^{* * *}$ & $-0.009^{* * *}$ & $-0.048^{* * *}$ \\
High types & $(0.078)$ & $(0.002)$ & $(0.001)$ & $(0.002)$ \\
& $-0.661^{* * *}$ & $0.024^{* * *}$ & $-0.005^{* * *}$ & $-0.026^{* * *}$ \\
Low types & $(0.110)$ & $(0.003)$ & $(0.001)$ & $(0.003)$ \\
Linear time trend & $-1.944^{* * *}$ & $0.059^{* * *}$ & $-0.012^{* * *}$ & $-0.067^{* * *}$ \\
Control variables & $(0.108)$ & $(0.003)$ & $(0.001)$ & $(0.003)$ \\
\hline
\end{tabular}

Robust standard errors are reported in brackets. $* * * \mathrm{p}<0.01,{ }^{*} \mathrm{p}<0.05,{ }^{*} \mathrm{p}<0.1$.

The whole sample consists of 118,618 observations, the sample of high types consists of 49,668 observations, the sample of low types consists of 68,950 observations.

Control variables include age, age $^{2}$, gender, marital status, state dummies, ethnicity, family income, family size, house ownership, dummy indicating whether the head of the household is employed, dummy indicating whether the respondent lives in a metropolitan area, Pell grant received, aggregate mean weekly earnings, aggregate tuition, nominal interest rate, inflation rate, mother's education and father's education. The full set of results for the first column is reported in Table A2 in the Appendix. 
Table 8: Sensitivity analysis - time trend and control variables

\begin{tabular}{|c|c|c|c|c|c|c|c|}
\hline \multicolumn{8}{|c|}{ Dependent variable: college enrollment ( $=1$ if enrolled in college, $=0$ otherwise) } \\
\hline & & & & $\ln (\mathrm{GDP})$ & & & \\
\hline Whole sample & $\begin{array}{c}-0.33^{* *} \\
(0.13)\end{array}$ & $\begin{array}{c}-0.56 * * * \\
(0.21)\end{array}$ & $\begin{array}{c}-1.12 * * * \\
(0.25)\end{array}$ & $\begin{array}{c}-0.66 * * * \\
(0.08)\end{array}$ & $\begin{array}{c}-1.20 * * * \\
(0.08)\end{array}$ & $\begin{array}{c}-0.56 * * * \\
(0.04)\end{array}$ & $\begin{array}{c}-1.38 * * * \\
(0.08)\end{array}$ \\
\hline High types & $\begin{array}{c}0.12 \\
(0.20)\end{array}$ & $\begin{array}{c}0.05 \\
(0.30)\end{array}$ & $\begin{array}{l}-0.43 \\
(0.35)\end{array}$ & $\begin{array}{c}-0.23^{* *} \\
(0.11)\end{array}$ & $\begin{array}{c}-0.59 * * * \\
(0.12)\end{array}$ & $\begin{array}{c}-0.32 * * * \\
(0.06)\end{array}$ & $\begin{array}{c}-0.67 * * * \\
(0.11)\end{array}$ \\
\hline Low types & $\begin{array}{c}-0.69 * * * \\
(0.18)\end{array}$ & $\begin{array}{c}-1.02 * * * \\
(0.28)\end{array}$ & $\begin{array}{c}-1.67 * * * \\
(0.34)\end{array}$ & $\begin{array}{c}-1.00 * * * \\
(0.11)\end{array}$ & $\begin{array}{c}-1.71 * * * \\
(0.11)\end{array}$ & $\begin{array}{c}-0.78 * * * \\
(0.06)\end{array}$ & $\begin{array}{c}-1.95 * * * \\
(0.11)\end{array}$ \\
\hline Quadratic time trend & $\checkmark$ & & & & & & \\
\hline Cubic time trend & & $\sqrt{ }$ & & & & & \\
\hline Quartic time trend & & & $\sqrt{ }$ & & & & \\
\hline Lag GDP & & & & $\sqrt{ }$ & & & \\
\hline College premium & & & & & $\sqrt{ }$ & & \\
\hline $\begin{array}{l}\text { Exclude controls at } \\
\text { aggregate level }\end{array}$ & & & & & & $\sqrt{ }$ & \\
\hline $\begin{array}{l}\ln (\mathrm{GDP}) * \ln (\text { family } \\
\text { income })\end{array}$ & & & & & & & $\checkmark$ \\
\hline
\end{tabular}

Robust standard errors are reported in brackets. $* * * \mathrm{p}<0.01, * * \mathrm{p}<0.05,{ }^{*} \mathrm{p}<0.1$.

The whole sample consists of 118,618 observations, the sample of high types consists of 49,668 observations, the sample of low types consists of 68,950 observations. Each regression includes the same control variables listed in Table 7 with one exception. The sixth regression does not include aggregate tuition, aggregate mean weekly earnings, nominal interest rate and inflation rate. 
Table 9: Sensitivity analysis - definition of ability types

\begin{tabular}{|c|c|c|c|c|c|c|}
\hline \multicolumn{7}{|c|}{ Dependent variable: college enrollment ( $=1$ if enrolled in PSE,$=0$ otherwise) } \\
\hline & $\begin{array}{c}\text { HIGH } \\
> \\
\text { high school } \\
\text { diploma }\end{array}$ & $\begin{array}{c}\text { LOW } \\
\leq \\
\text { high school } \\
\text { diploma }\end{array}$ & $\begin{array}{c}\text { HIGH } \\
\geq \\
\text { Bachelor's } \\
\text { degree }\end{array}$ & $\begin{array}{c}\text { LOW } \\
< \\
\text { Bachelor's } \\
\text { degree }\end{array}$ & $\begin{array}{c}\text { HIGH } \\
\geq \\
\text { Grade } 12\end{array}$ & $\begin{array}{c}\text { LOW } \\
< \\
\text { Grade } 12\end{array}$ \\
\hline $\operatorname{Ln}(\mathrm{GDP})$ & $\begin{array}{c}-0.661 * * * \\
(0.109)\end{array}$ & $\begin{array}{c}-1.944 * * * \\
(0.108)\end{array}$ & $\begin{array}{l}-0.230 \\
(0.157)\end{array}$ & $\begin{array}{c}-1.428 * * * \\
(0.092)\end{array}$ & $\begin{array}{c}-0.829 * * * \\
(0.086)\end{array}$ & $\begin{array}{c}-2.16^{* * *} \\
(0.198)\end{array}$ \\
\hline $\mathrm{N}$ & 49,668 & 68,950 & 21,279 & 97,339 & 100,639 & 17,979 \\
\hline
\end{tabular}




\section{Appendix}

Table A1: Data sources for the empirical analysis

\begin{tabular}{ll}
\hline \hline Variable & Source \\
\hline GDP: & US Bureau of Economic Analysis \\
Unemployment rate: & US Bureau of Labor Statistics \\
Employment rate: & US Bureau of Labor Statistics \\
Industrial Production: & US Bureau of Economic Analysis \\
Interest rate: & World Bank \\
Inflation rate (calculated from CPI) & US Bureau of Labor Statistics \\
Tuition: & National Centre for Education Statistics \\
Other controls: & Current Population Survey and American Time \\
& Use Survey \\
\hline
\end{tabular}


Table A2: Average marginal effects from probit estimation

\begin{tabular}{|c|c|c|c|c|c|c|}
\hline \multicolumn{7}{|c|}{ Dependent variable: college enrollment ( $=1$ if enrolled in PSE, $=0$ otherwise) } \\
\hline \multirow[b]{2}{*}{ Variable } & \multicolumn{2}{|c|}{ WHOLE SAMPLE } & \multicolumn{2}{|c|}{ HIGH TYPES } & \multicolumn{2}{|c|}{ LOW TYPES } \\
\hline & dydx & (Std. Err.) & dydx & (Std. Err.) & dydx & (Std. Err.) \\
\hline $\ln (\mathrm{GDP})$ & $-1.365 * * *$ & $(0.078)$ & $-0.661 * * *$ & $(0.110)$ & $-1.944 * * *$ & $(0.108)$ \\
\hline Age & $-0.055^{* * *}$ & $(0.001)$ & $-0.058 * * *$ & $(0.001)$ & $-0.054 * * *$ & $(0.001)$ \\
\hline Female & $0.071 * * *$ & $(0.003)$ & $0.050 * * *$ & $(0.004)$ & $0.085 * * *$ & $(0.004)$ \\
\hline Married & $-0.220 * * *$ & $(0.015)$ & $-0.213 * * *$ & $(0.025)$ & $-0.226 * * *$ & $(0.019)$ \\
\hline $\mathrm{DSW}^{1}$ & $-0.151 * * *$ & $(0.016)$ & $-0.148 * * *$ & $(0.024)$ & $-0.155 * * *$ & $(0.021)$ \\
\hline $\ln ($ family income $)$ & 0.002 & $(0.002)$ & $0.017 * * *$ & $(0.003)$ & $-0.006 * *$ & $(0.002)$ \\
\hline $\ln ($ family size $)$ & $-0.046 * * *$ & $(0.006)$ & $-0.039 * * *$ & $(0.009)$ & $-0.052 * * *$ & $(0.008)$ \\
\hline House ownership & $0.075^{* * *}$ & $(0.005)$ & $0.076 * * *$ & $(0.009)$ & $0.075 * * *$ & $(0.006)$ \\
\hline Head of HH employed & $0.023 * * *$ & $(0.004)$ & $0.013^{*}$ & $(0.007)$ & $0.029 * * *$ & $(0.006)$ \\
\hline Metropolitan area & $0.038 * * *$ & $(0.005)$ & $0.013^{*}$ & $(0.007)$ & $0.048 * * *$ & $(0.006)$ \\
\hline Pell Grant*1,000 & $0.055^{* * *}$ & $(0.003)$ & $0.034 * * *$ & $(0.003)$ & $0.074 * * *$ & $(0.006)$ \\
\hline Mean weakly earnings $* 1,000$ & $0.025 * * *$ & $(0.002)$ & $0.014 * * *$ & $(0.003)$ & $0.032 * * *$ & $(0.003)$ \\
\hline Tuition & $0.122 * * *$ & $(0.029)$ & $0.128 * * *$ & $(0.043)$ & $0.113 * * *$ & $(0.040)$ \\
\hline Nominal interest rate & $0.004 * *$ & $(0.001)$ & -0.000 & $(0.002)$ & $0.006 * * *$ & $(0.002)$ \\
\hline Inflation & $0.023 * * *$ & $(0.002)$ & $0.011 * * *$ & $(0.003)$ & $0.034 * * *$ & $(0.003)$ \\
\hline Linear time trend & $0.046 * * *$ & $(0.004)$ & $0.015^{* *}$ & $(0.006)$ & $0.072 * * *$ & $(0.006)$ \\
\hline \multicolumn{7}{|c|}{ Mother's education (compared to $>$ high school diploma): } \\
\hline$<$ high-school diploma & $-0.096 * * *$ & $(0.005)$ & & & $-0.105 * * *$ & $(0.007)$ \\
\hline$=$ high school diploma & $-0.101 * * *$ & $(0.004)$ & - & - & $-0.089 * * *$ & $(0.006)$ \\
\hline \multicolumn{7}{|c|}{ Father's education (compared to $>$ high school diploma): } \\
\hline$<$ high-school diploma & $-0.121 * * *$ & $(0.005)$ & - & - & $-0.123 * * *$ & $(0.006)$ \\
\hline$=$ high-school diploma & $-0.113 * * *$ & $(0.004)$ & - & - & $-0.104 * * *$ & $(0.006)$ \\
\hline Observations & 118,618 & & 49,668 & & 68,950 & \\
\hline
\end{tabular}

Robust standard errors are reported in brackets. The regression also includes ethnicity dummies and state dummies. There are no estimates for parental education in the high types group because the corresponding dummy variables are equal zero for this group. Average Weakly Earnings refers to earnings in non-agricultural sectors in 1985 constant dollars. Family income, tuition and Pell Grants are in 1985 constant dollars as well. The full set of results is reported in Table A2.

1. DSW: divorced/separated/widowed.

$* * * \mathrm{p}<0.01, * * \mathrm{p}<0.05, * \mathrm{p}<0.1$ 


\section{References}

Bell, F. C., Miller, M. L., 2002. Life tables for the united states social security area. Actuarial Study, Social Security Administration 116.

Ben-Porath, Y., 1967. The production of human capital and the life cycle of earnings. Journal of Political Economy 75 (4), 352-365.

Benhabib, J., Rogerson, R., Wright, R., 1991. Homework in macroeconomics: household production and aggregate fluctuations. Journal of Political Economy 99 (6), 1166-87.

Betts, J., McFarland, L., 1995. Safe port in a storm: the impact of labor market conditions on community college enrollments. Journal of Human Resources 30, 741-765.

Canton, E., 2002. Business cycles in a two-sector model of endogenous growth. Economic Theory $19(3), 477-492$.

Carneiro, P., Heckman, J., 2003. Inequality in America: What Role for Human Capital Policies? Cambridge, Mass: MIT Press, Ch. Human capital policy.

Christian, M. S., 2007. Liquidity constraints and the cyclicality of college enrollment in the united states. Oxford Economic Papers 59, 141-169.

Cunha, F., Heckman, J. J., Lochner, L., Masterov, D. V., 2006. Interpreting the evidence on life cycle skill formation. Handbook of the Economics of Education 1, 697-812.

Davern, M., Jones, A., Lepkowski, J., Davidson, G., Blewett, L. A., 2006. Unstable inferences? an examination of complex survey sample design adjustments using the current population survey for health services research. Inquiry 3 (43), 283-297.

Davern, M., Jones, A., Lepkowski, J., Davidson, G., Blewett, L. A., 2007. Estimating regression standard errors with data from the current population survey's public use file. Inquiry - Excellus Health Plan 2 (44), 211-224. 
DeJong, D. N., Ingram, B. F., 2001. The cyclical behavior of skill acquisition. Review of Economic Dynamics 4, 536-561.

Dellas, H., Koubi, V., 2003. Business cycle and schooling. European Journal of Political Economy $19,843-859$.

Dellas, H., Sakellaris, P., 2003. On the cyclicality of schooling: theory and evidence. Oxford Economic Papers 55, 148-172.

Edwards, L. N., 1976. School retention of teenagers over the business cycle. Journal of Human Resources 11, 200-208.

Einarsson, T., Marquis, M. H., 1998. An RBC model with growth: the role of human capital. Journal of Economics and Business 50, 431-444.

Gomme, P., Rogerson, R., Rupert, P., Wright, R., 2005. The Business Cycle and the Life Cycle. In: NBER Macroeconomics Annual 2004, Volume 19. NBER Chapters. National Bureau of Economic Research, Inc, pp. 415-592.

Haley, W. J., 1976. Estimation of the earnings profile from optimal human capital accumulation. Econometrica 44 (6), 1223-1238.

Hansen, G. D., 1985. Indivisible labor and the business cycle. Journal of Monetary Economics $16(3), 309-327$.

Hansen, G. D., 1993. The cyclical and secular behavior of the labor input: Comparing efficiency units and hours worked. Journal of Applied Econometrics 8 (1), 71-80.

Hansen, G. D., İmrohoroğlu, S., 2009. Business cycle fluctuations and the life cycle: How important is on-the-job skill accumulation. Journal of Economic Theory 144, 2293-2309.

Heckman, J. J., 1976. A life-cycle model of earnings, learning, and consumption. Journal of Political Economy 84 (4), S11-S44.

Heer, B., Maussner, A., 2009. Dynamic general equilibrium modeling. Springer 2ed., Berlin. 
Heylen, F., Pozzi, L., 2007. Crises and human capital accumulation. Canadian Journal of Economics 40 (4), 1261-1285.

Huggett, M., Ventura, G., Yaron, A., 2011. Sources of lifetime inequality. American Economic Review 7, 2923-54.

Johnson, T., Hebein, F. J., 1974. Investments in human capital and growth in personal income. The American Economic Review 64 (4), 604-615.

Kane, T. J., 1994. College entry by blacks since 1970: the role of college costs, family background, and the returns to education. Journal of Political Economics 102, 878-911.

Kydland, F. E., 1984. Labor-force heterogeneity and the business cycle. Carnegie-Rochester Conference Series on Public Policy 21, 173-208.

Maliar, L., Maliar, S., 2001. Heterogeneity in capital and skills in a neoclassical stochastic growth model. Journal of Economic Dynamics and Control 25, 1367-1397.

Mattila, J. P., 1982. Determinants of male school enrollments: a time-series analysis. Review of Economics and Statistics 64, 242-51.

Méndez, F., Sepúlveda, F., 2012. The cyclicality of skill acquisition: evidence from panel data. American Economic Journal: Macroeconomics 4 (3), 128-152.

Perli, R., 1998. Indeterminacy, home production, and the business cycle: a calibrated analysis. Journal of Monetary Economics 41, 105-125.

Polzin, P. E., 1984. The impact of economic trends on higher education enrollment. Growth and change $15,18-22$.

Prescott, E. C., 1986. Theory ahead of business cycle measurement. Carnegie Rochester Series on Public Policy 3, 51-77.

Ravn, M. O., Uhlig, H., 2002. Notes on adjusting the hodrick-prescott filter for the frequency of observations. The Review of Economics and Statistics 84 (2), 371-380. 
Ríos-Rull, V., 1993. Working in the market, working at home, and the acquisition of skills: a general-equilibrium approach. American Economic Review 8 (4), 893-907. 